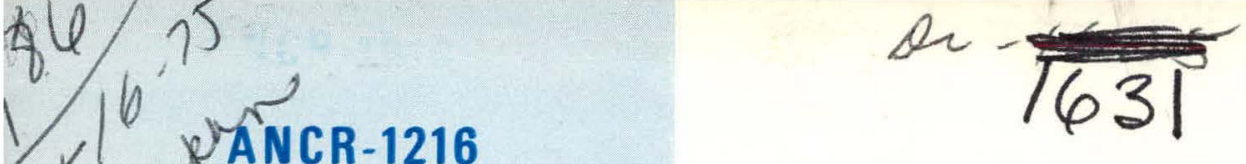

NRC-2

\title{
TWO-PHASE FLOW VELOCITY MEASUREMENT WITH RADIATION INTENSITY CORRELATION
}

\author{
G.D. Lassahn
}

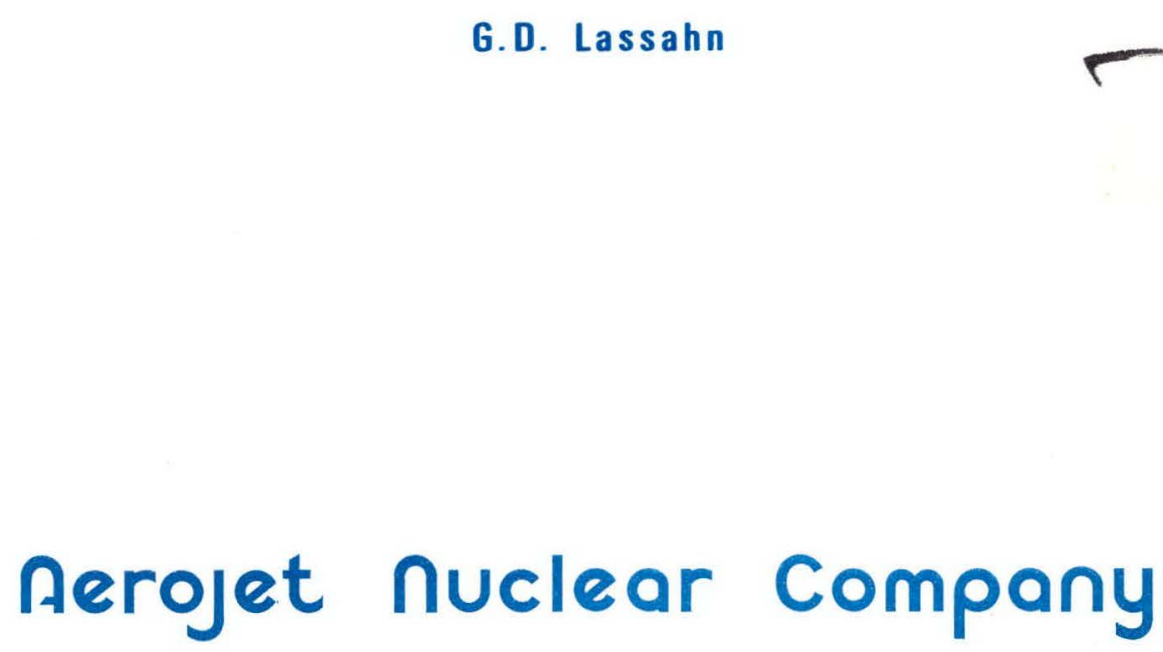

IDAHO NATIONAL ENGINEERING LABORATORY

Idaho Falls, Idaho - 8340 I

$2 B$

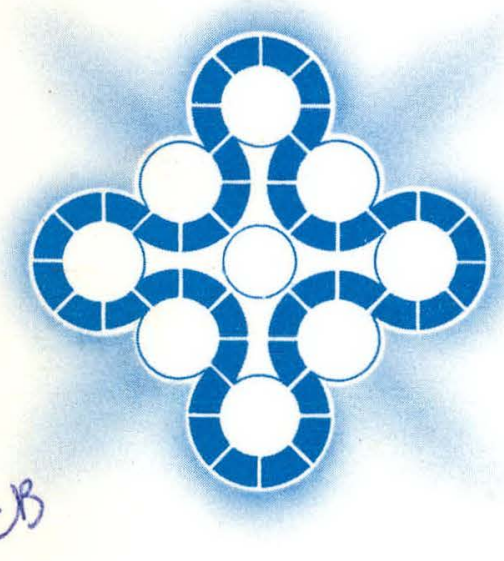

MASTER

DISTRIBUTION OF THIS DOCUMENT IS UNLIMITED. DATEPUBLISHED-JUNE 1975

PREPARED FOR THE

ENERGY RESEARCH AND DEVELOPMENT ADMINISTRATION IDAHO OPERATIONS OFFICE UNDER CONTRACT E (10-1)-1375 


\section{DISCLAIMER}

This report was prepared as an account of work sponsored by an agency of the United States Government. Neither the United States Government nor any agency Thereof, nor any of their employees, makes any warranty, express or implied, or assumes any legal liability or responsibility for the accuracy, completeness, or usefulness of any information, apparatus, product, or process disclosed, or represents that its use would not infringe privately owned rights. Reference herein to any specific commercial product, process, or service by trade name, trademark, manufacturer, or otherwise does not necessarily constitute or imply its endorsement, recommendation, or favoring by the United States Government or any agency thereof. The views and opinions of authors expressed herein do not necessarily state or reflect those of the United States Government or any agency thereof. 


\section{DISCLAIMER}

Portions of this document may be illegible in electronic image products. Images are produced from the best available original document. 


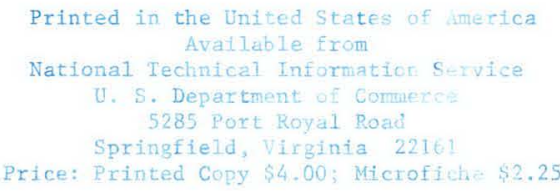

Price: Printed Copy $\$ 4.00 ;$ Microfiche $\$ 2.25$

This report was prepared as an account of work sponsored by the United States Government. Neither the United States nor the Energy Research and Development Administration, nor any of their employees, nor any of their contractors, subcontractors, or thei employees, makes any warranty, express or implied, or assumes any legal liability or responsibility for the accuracy, completeness or usefulness of any information, apparatus, product or process disclosed, or represents that its use would not infringe privately owned rights. 


\section{RADIATION INTENSITY CORRELATION}

by

G. D. Lassahn

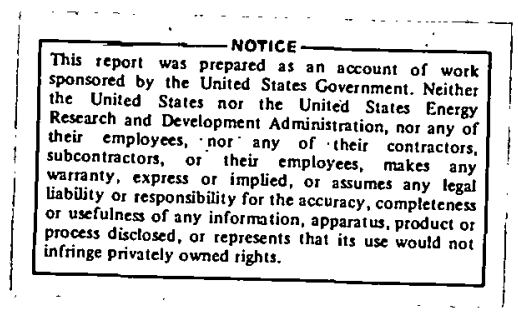

AEROJET NUCLEAR COMPANY

DATE PUBLISHED - JULY 1975

PREPARED FOR THE

ENERGY RESEARCH AND DEVELOPMENT ADMINISTRATION

IDAHO OPERATIONS OFFICE

UNDER CONTRACT NO. AT(10-1)-1375 


\section{ACKNOWLEDGMENTS}

B. D. Stoddard and D. Phetteplace were instrumental in setting up the experiment, and T. C. Piper and A. E. Arave gave suggestions on the experimental procedure. C. J. Buchenauer suggested several of the variations of the basic technique. 


\begin{abstract}
Two-phase flow velocities can be measured by correlating' radiation attenuation, radiation emission, or radiation scattering at several positions along the pipe length. This report gives a description of a basic two-phase flow velocity measuring system and some variations of that system. A mathematical treatment of the basic system and a description of a simple experimental confirmation of the principle are also included.
\end{abstract}




\section{CONTENTS}

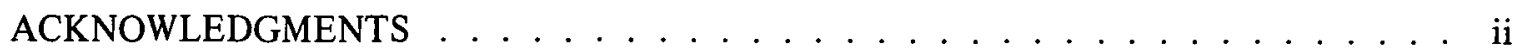

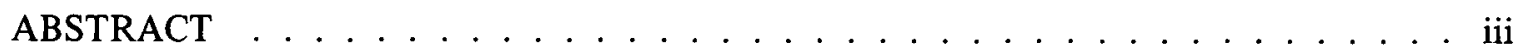

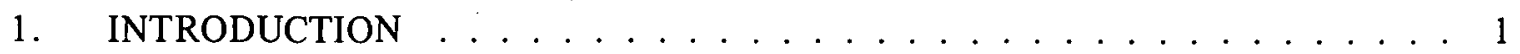

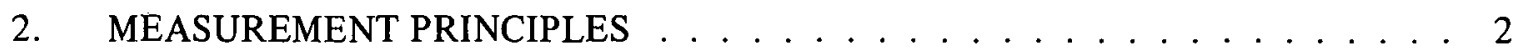

3. MATHEMATICAL TREATMENT ................. 4

3.1 The Periodicity Function . . . . . . . . . . . . . . 8

3.2 The Source Distribution Function for a Spherical Bubble . . . . . . . . 10

3.3 The Slot Geometry Function . . . . . . . . . . . . . . . . 12

3.4 A Special Case: $k=2 b \ldots \ldots \ldots . \ldots . \ldots 14$

3.5 Some Application Notes . . . . . . . . . . . . . . . . . . 14

4. AN ABSORBING FLUID WITH AN EXTERNAL RADIATION SOURCE . . . 20

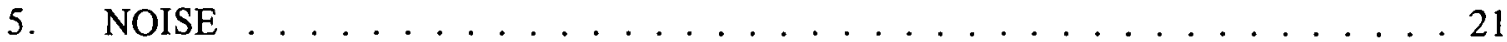

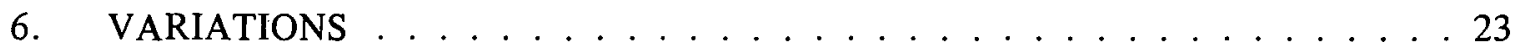

7. EXPERIMENTAL DEMONSTRATION ................. 26

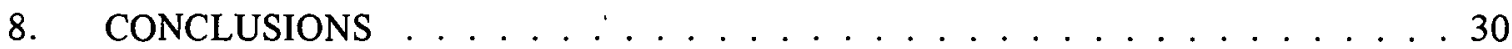

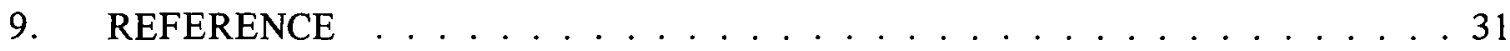

FIGURES

1. Essential elements of the basic system . . . . . . . . . . . . . 2

2. Slot geometry and coordinate system ................ 5

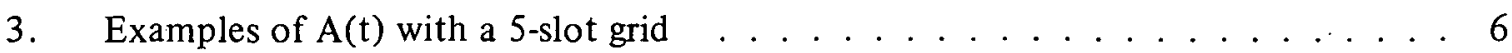

4. Examples of the periodicity function . . . . . . . . . . . . 9

5. The R dependence of $D_{z} \ldots \ldots \ldots \ldots \ldots$

6. The $\mathrm{z}$ dependence of $\mathrm{I}_{\delta} \ldots \ldots \ldots \ldots$

7. Relative signal amplitude versus $\mathrm{x}_{\mathrm{o}}$, for fixed $\mathrm{L}$, with $\mathrm{k}=2 \mathrm{~b} \ldots \ldots$. . . . . . 15 
8. Relative signal amplitude versus $L$ for fixed $x_{0}$, with $k=2 b \ldots \ldots$

9. Sensitivity versus $x_{0}$ for different $L$ values, for a single-grid, pipe-averaging system ........................ 17

10. Sensitivity versus $x_{0}$ for different $L$ values, for a dual-grid,

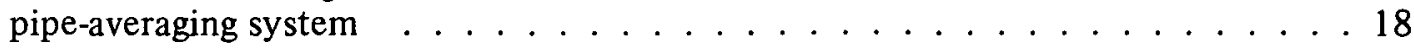

11. Sensitivity versus $x_{0}$, with sensitivity maximized at the pipe center, for a single-grid system . . . . . . . . . . . . . . . . . . 19

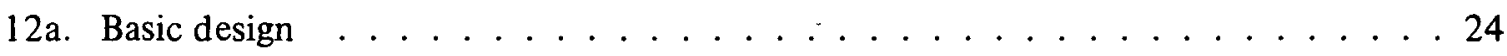

12b. Separate source and detector for each slot . . . . . . . . . . 24

12c. Source-detector pairs rotated to reduce the area of sensitivity . . . . . . 24

13. A different grid configuratiun, and a wräp-around design . . . . . . . . 25

14. Photograph of the experimental apparatus .............. 27

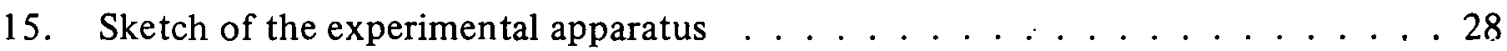

16. Sample spectra from experiment ... . . . . . . . . . . . 29 


\section{TẂO-PHASE FLOW VELOCITY MEASUREMENT WITH \\ RADIATION INTENSITY CORRELATION}

\section{INTRODUCTION}

The measurement technique described in this report is intended for measuring the flow velocities of inhomogeneous steam-water mixtures encountered in nuclear reactor simulation and testing. However, the general technique can probably be applied to a wide variety of inhomogeneous two-phase flow systems.

This technique has the potential for measuring velocities either at a localized region inside a pipe or averaged over the whole of the pipe. The fluid flow is not disturbed, except that the fluid is irradiated. The technique is basically a transit time measurement which makes use of the difference in the radiation interaction properties of the two phases. A Fourier analysis is used to extract the transit time information from the signal-noise mixture. 


\section{MEASUREMENT PRINCIPLES}

The basic apparatus is sketched in Figure 1. Radiation is. incident from the right. It passes through the pipe containing the fluid and through a grid, which consists of a series of slots in an opaque material. The radiation that passes through the slots then enters a detector: The electrical output from the detector is fed into a spectrum analyzer.

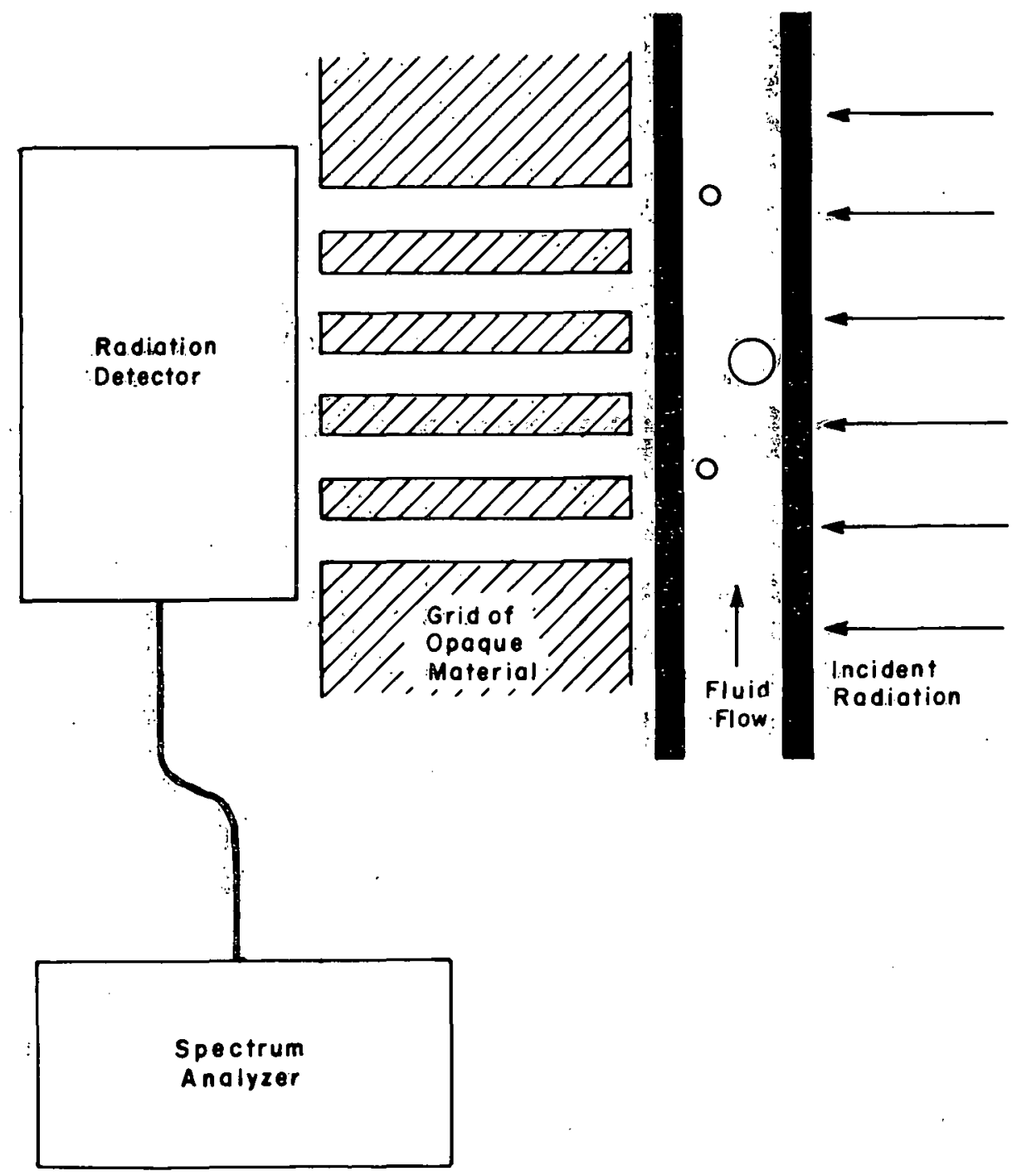

$\triangle N C-A-5102$

Fig. 1 Essential elements of the basic system.

The radiation must be able to pass through the pipe, and it must have significantly different attenuation coefficients in the two fluid phases present in the pipe. Neutron radiation might be best for water and air in a steel pipe, for example, although gamma radiation:might also be acceptable. The fluid must have rather large inhomogeneities, such as large bubbles in a liquid or, even better, slug flow. 
Consider a bubble in a liquid, as an example. The bubble is less absorbing than the liquid. When the bubble is in front of an opaque part of the grid, it has no effect on the output of the radiation detector; but, when the bubble is in front of a slot in the grid, it allows extra radiation to enter the detector. Hence, each time the bubble passes in front of a slot, the output of the radiation detector rises; as the bubble moves past a series of evenly spaced slots, the detector puts out a series of pulses evenly spaced in time (in addition to the normal DC output). The Fourier transform of this pulse train has a fundamental frequency proportional to the bubble velocity. That is, the spectrum analyzer connected to the radiation detector shows a peak at a frequency $f=v / k$, where $v$ is the bubble velocity and $k$ is the slot spacing, center to center. If several bubbles with different velocities are in the sampled region simultaneously, the spectrum analyzer shows a separate peak for each of the several bubble velocities. 


\section{MATHEMATICAL TREATMENT}

A mathematical analysis. will be done for the easiest system, in which the fluid itself is the radiation source. This system is nearly equivalent to a system with an external radiation source and an absorbing fluid. The conditions for this equivalence will be discussed later.

The analysis presented here makes the following assumptions:

(1) At least one of the two fluid phases is radioactive, and the two fluid phases are not equally radioactive in terms of radiation quanta emitted per time per volume of fluid.

(2) Neither phase of the fluid absorbs or scatters a significant amount of the radiation.

(3) The grid material is a perfect absorber.

For convenience, the two-phase fluid will be referred to as a liquid with gas bubbles, although the analyșis is applicable to other two-phase fluids.

Let $\mathrm{D}_{\mathrm{xyz}}(\mathrm{x}, \mathrm{y}, \mathrm{z}, \mathrm{t})$ be the radiation source distribution; that is, the total radiation intensity integrated over the surface of an arbitrary volume of the fluid is

$$
\iint \vec{s} \cdot d \vec{A}=\iiint D_{x y z}(x, y, z, t) d x d y d z
$$

where $\vec{S}$ is the Poynting vector or the particle flux, whichever is appropriate. $\left(D_{x y z}\right.$ is the divergence of $\vec{S}$.) From a point source of radiation at $(x, y, z)$, let $I_{\delta}(\dot{x}, y, z)$ be the fraction of the radiation intensity which passes through a slot with its front face centered at the coordinate system origin, as indicated in Figure 2. Then the total radiation flux through this slot from the source distribution $\mathrm{D}_{\mathrm{xyz}}$ is

$$
I_{0}(t)=\iiint_{\substack{\text { all } \\ \text { fluid }}} I_{\delta}(x, y, z) D_{x y z}(x, y, z, t) d x d y d z .
$$

Let $\mathrm{k}$ be the distance between the centers of neighboring slots. Then the flux through the $\mathrm{j}$ th slot, with its front centered at $(0,0, \mathrm{kj})$, is

$$
I_{j}(t)=\iiint I_{\delta}(x, y, z) D_{x y z}(x, y, z+j k, t) d x d y d z .
$$




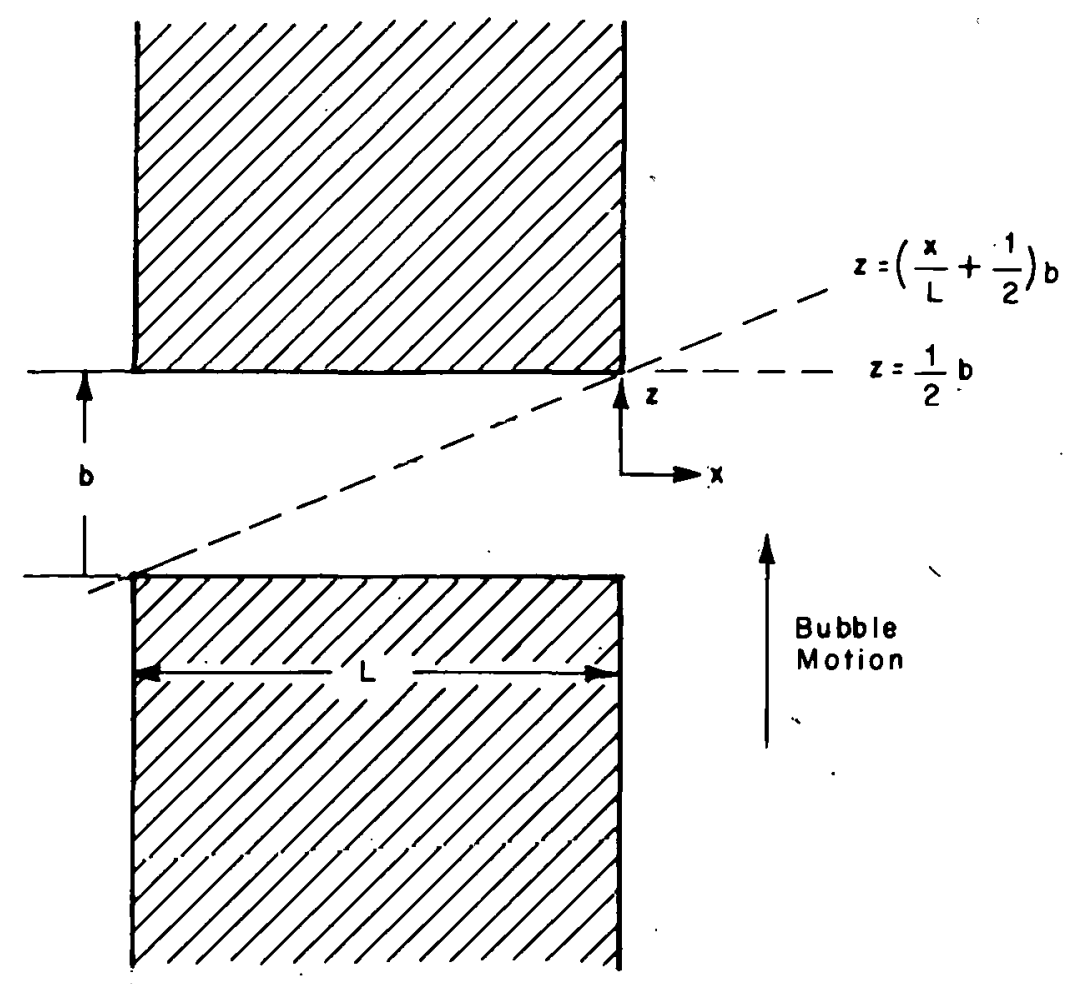

Side view

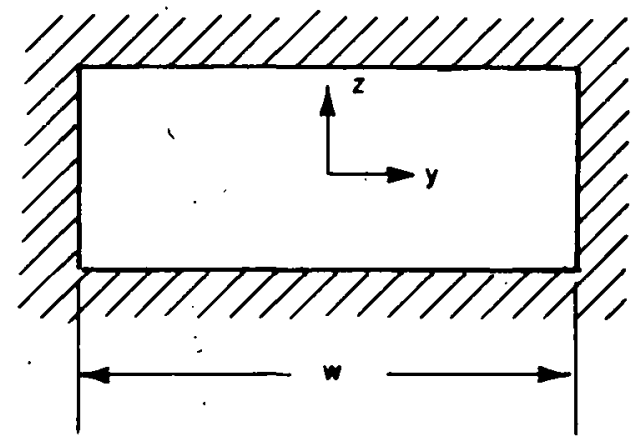

Front View

Fig. 2 Slot geometry and coordinate system.

ANC-A - 5103

The total flux through a series of $\mathrm{N}$ such slots is a simple sum:

$$
I_{T}(t)=\sum_{j=1}^{N} I_{j .}(t) .
$$

The voltage versus time output of the radiation detector that senses the radiation through all the slots simultaneously is $\mathrm{A}(\mathrm{t})=a \mathrm{I}_{\mathrm{T}}(\mathrm{t})$, where $a$ is just a proportionality constant. Note the examples of $A(t)$ in Figure 3.

The quantity of interest is the frequency spectrum of $A(t)$, or its Fourier transform. This transform is

$$
A(\omega)=\frac{1}{\sqrt{2 \pi}} \int_{-\infty}^{+\infty} A(t) e^{-1 \omega t} d t
$$

where $\omega$ is the usual angular frequency, or $2 \pi$ times the frequency in cycles per second. Then, 

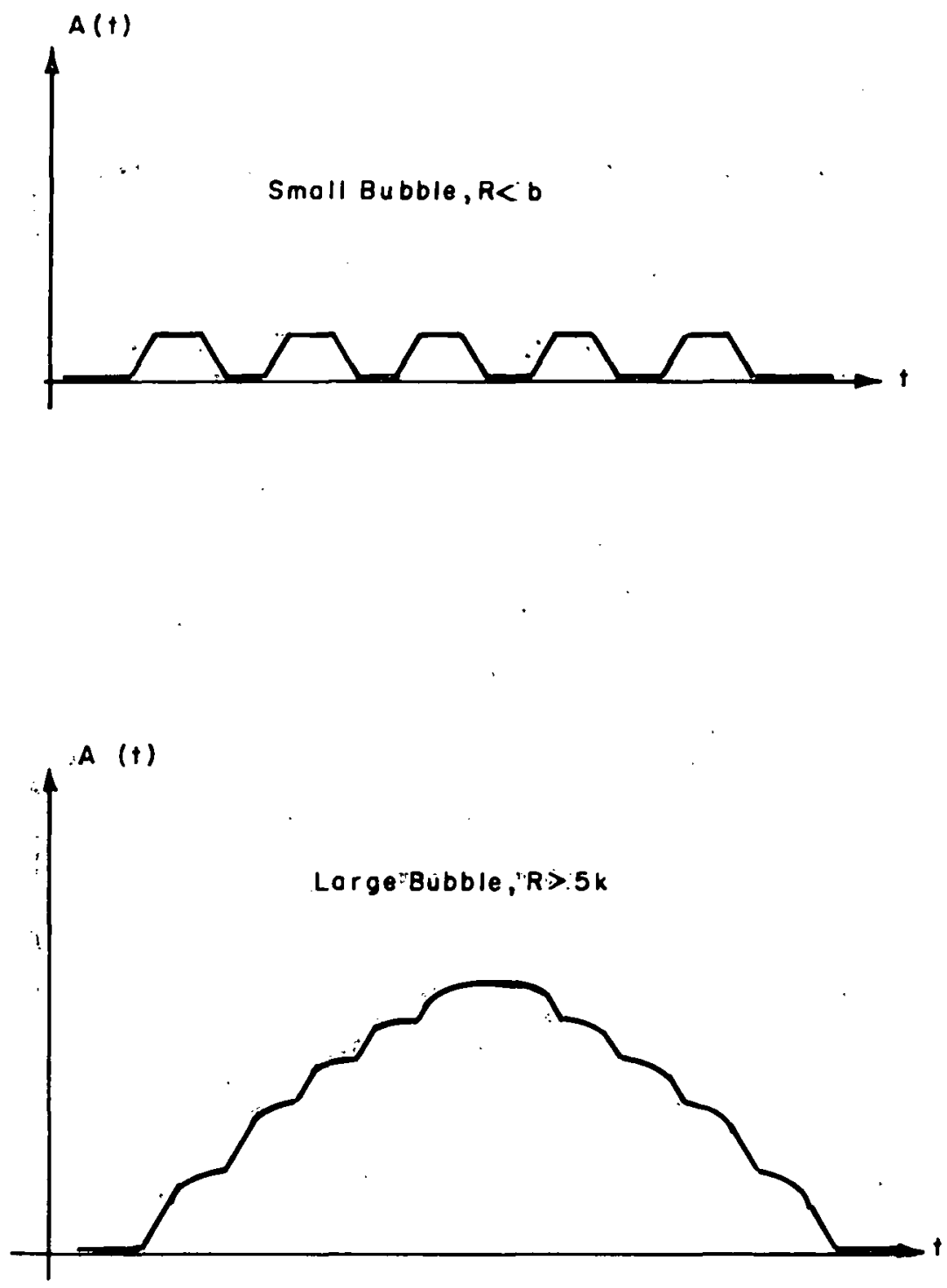

Fig. 3 Examples of $A(t)$ with a 5-slot grid.

ANC-A- 5104

$$
\begin{aligned}
& \therefore(\omega)=\frac{\alpha}{\sqrt{2 \pi}} \int_{-\infty}^{+\infty} \sum_{j=1}^{N} \iint_{\substack{\text { all } \\
\text { fluid }}} I_{\delta}(x, y, z) D_{x y . z}(x, y, z+j k, t) \\
& \text { dxdydz } e^{-i \omega t} d t .
\end{aligned}
$$

If the fluid is flowing with velocity $\mathrm{v}$ in the $\mathrm{z}$ direction, then

$$
D_{x y z}(x, y, z, t)=D_{x y z}(x, y, z-v t, 0)
$$

6. 
and

$$
\begin{aligned}
& A(\omega)=\frac{\alpha}{\sqrt{2 \pi}} \int \sum_{j} \iiint I_{\delta}(x, y, z) D_{x y z}(x, y, z+j k-v t, 0) d x d y d z e^{-i \omega t} d t \\
& =\frac{\alpha}{\sqrt{2 \pi}} \int \sum_{j} \iiint I_{\delta}(x, y, z) D_{x y z}(x, y, u, 0) \exp \left(-i \omega \frac{2+j k-u}{v}\right) \operatorname{dxdyd} z d u \frac{1}{v} \\
& =\frac{\alpha}{v \sqrt{2 \pi}} \iint_{a l 1}\left\{\int_{\delta} I_{\delta}(x, y, z) e^{-i \frac{\omega z}{v}} d z \int_{-\infty}^{+\infty} D_{x y z}(x, y, u, 0) e^{i \frac{\omega u}{v}} d u\right\} \\
& \text { fluid } \\
& \operatorname{dyd} x \sum_{i=1}^{N} e^{-i \frac{j k \omega}{v}}
\end{aligned}
$$

It will simplify the procedure to write $\mathrm{D}_{\mathrm{xyz}}$ as

$$
D_{x y z}(x, y, z, t)=D_{x y z}^{\prime}(x, y, z, t)+D^{\prime \prime}
$$

where $D^{\prime \prime}$ is the (constant) source distribution. for the liquid with no bubbles. Obviously, then, $D_{x y z}^{\prime}$ is nonzero only where there is a bubble. Using Equation (9) in Equation (8), we get two terms for $\mathrm{A}(\omega)$. $\mathrm{D}^{\prime \prime}$ contributes an uninteresting zero-frequency (DC) component to $A(\omega)$, which will henceforth be ignored. (This DC component may be useful in determining the fluid density, which is a separate problem.) In the $D_{x y z}^{\prime}$ term, the range of integration over $x$ and $y$ can be reduced to that range in which $D_{x y z}^{\prime}$ is not zero, which is just the $x-y$ area occupied by a bubble. We then have

$$
\begin{gathered}
\left.A(\omega)=\frac{\alpha}{\sqrt{2 \pi}} \int_{\substack{\text { bubble } \\
\text { area }}} \int_{\delta} I_{\delta}(x, y, z) e^{-i \frac{\omega z}{v}} d z \int_{\substack{\text { bubble } \\
\text { area }}} D_{x y z}^{\prime}(x, y, u, 0) e^{i \frac{\omega u}{v}} d u\right] \\
\operatorname{dydx} \sum_{j=1}^{n} e^{-i \frac{j k \omega}{v}} .
\end{gathered}
$$


A "small bubble" approximation is required for further simplification of the mathematics. It seems obvious from physical considerations that larger bubbles should give larger signals and better velocity indications. An analysis for small bubbles should give reasonable insight into the system's response to larger bubbles also. In view of the convenience and adequacy of considering only small bubbles, we will use a small bubble approximation: the $\mathrm{x}$ and $\mathrm{y}$ dimensions of the bubble are small compared with the $\mathrm{x}$ and $\mathrm{y}$ dimensions of a slot in the grid, so that $I_{\delta}(x, y, z)$ is nearly constant over the entire $x-y$ area of the bubble. (There is no restriction on the $\mathrm{z}$ dimension of the bubble.) With this assumption, $I_{\delta}$ and the entire $z$ integral can be treated as a constant in the $x y$ integration, and Equation (10) becomes

$A(\omega)=\frac{\alpha}{v \sqrt{2 \pi}} \int I_{\delta}\left(x_{0}, y_{0}, z\right) e^{-i \frac{\omega z}{v}} d z \int D_{z}(u) e^{i \frac{(1) u}{v}} d u \sum_{j} e^{-i \frac{j k \omega}{v}}$

where

$$
D_{z}(z)=\int_{\substack{\text { bubble } \\ \text { area }}} \int_{x y z}^{\prime}(x, y, z, 0) d y d x
$$

and $x_{0}$ and $y_{0}$ are the $x$ and $y$ coordinates of the bubble's center. Writing the Fourier transforms over $\mathrm{z}$ of $\mathrm{I}_{\delta}$ and $\mathrm{D}_{\mathrm{Z}}$ as $I_{\delta}$ and $D_{\mathrm{z}}$, and writing the sum as $P$, we have

$$
\mathrm{A}(\omega)=\frac{\alpha \sqrt{2 \pi}}{\mathrm{v}} I_{\delta}\left(\frac{\omega}{\mathrm{v}}\right) D_{\mathrm{z}}^{*}\left(\frac{\omega}{\mathrm{v}}\right) P\left(\frac{\omega \mathrm{k}}{\mathrm{v}}\right) \text {. }
$$

Note that this is the product of three functions of $\omega / v$; the first depends only on the geometry of a single slot, the second depends only on the geometry of the bubble, and the third depends only on the grid periodicity. The periodicity function $P$ is usually a series of sharp peaks, and the other two functions $I_{\delta}$ and $D_{\mathrm{z}}$ generally vary somewhat more slowly than $P$. It is convenient to regard the product $I_{\delta} D_{\mathrm{Z}}^{*}$ as an envelope or an amplitude modulation of the spikes represented by $P$.

\subsection{The Periodicity Function}

If the slots are uniformly spaced, then

$$
P * P=\frac{1-\cos \left(N \frac{\omega k}{v}\right)}{1-\cos \left(\frac{\omega k}{v}\right)}
$$

where $\mathrm{N}$ is the number of slots and $\mathrm{k}$ is the slot spacing, center to center. This function consists of a series of evenly spaced primary peaks of height $\mathrm{N}^{2}$, and a number of smaller peaks. The primary peaks become narrower as $\mathrm{N}$ increases, with the width being roughly inversely proportional to N. Note the examples of this function sketched in Figure 4. 


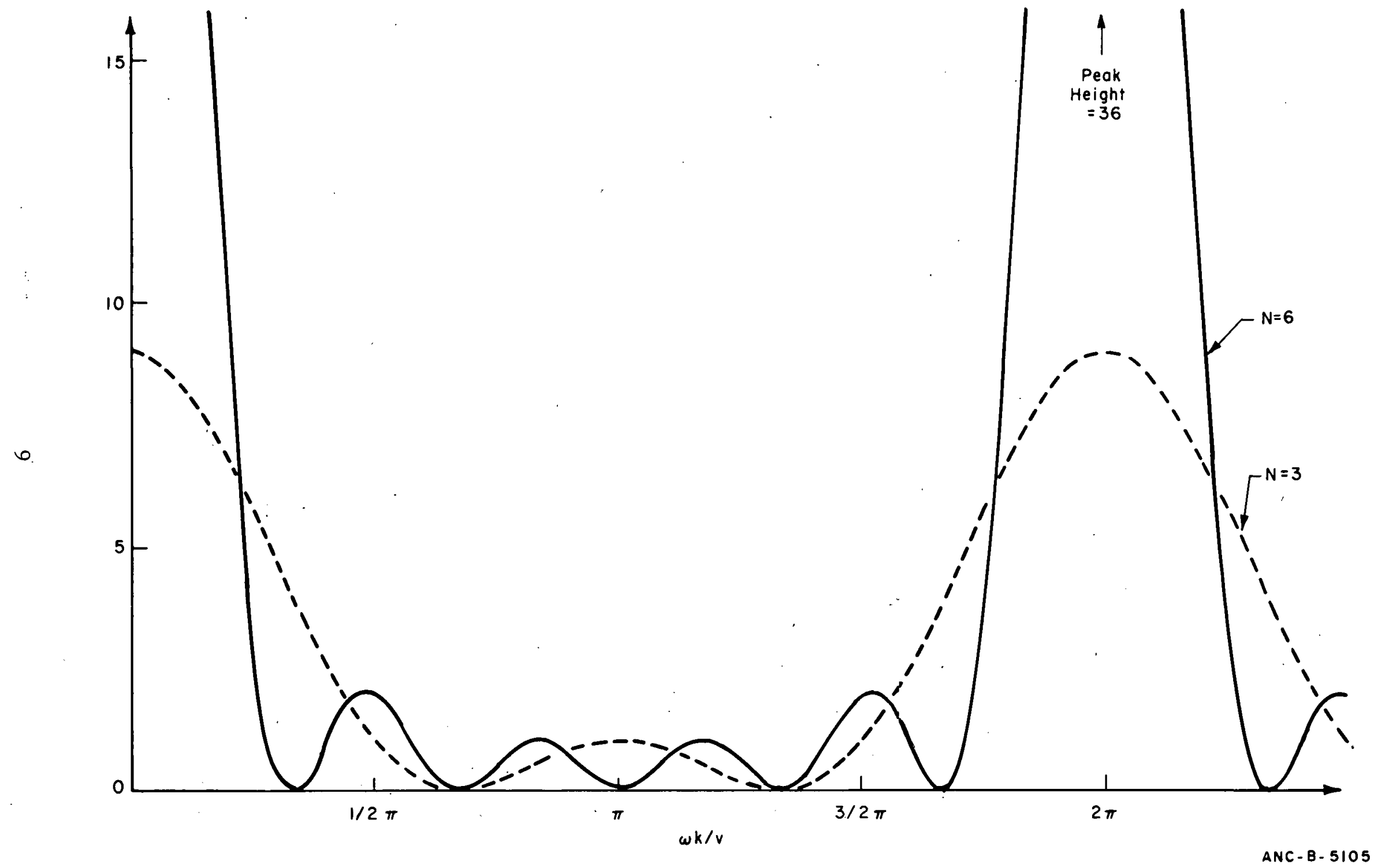

Fig. 4 Examples of the periodicity function. 
The first nonzero-frequency peak of $P^{*} P$ is the fluid velocity indicator. It occurs at $\omega$ $=2 \pi \mathrm{v} / \mathrm{k}$. Whether this peak is detectable is determined largely by its amplitude, as modified by the product $I_{\delta} D_{\mathrm{Z}}^{*}$. Therefore, it is desirable to know the values of the functions $I_{\delta}$ and $D_{\mathrm{Z}}$ at $\omega=2 \pi \mathrm{v} / \mathrm{k}$, and how these depend on the design parameters of the system and on the bubble size and position.

\subsection{The Source Distribution Function for a Spherical Bubble}

For a spherical bubble of radius $\mathrm{R}$, located at $\mathrm{z}=0$ when $\mathrm{t}=0, \mathrm{D}_{\mathrm{Z}}$ and $D_{\mathrm{Z}}$ are not hard to calculate. It is convenient to consider a moving coordinate system centered in the bubble. Obviously, $\mathrm{D}_{\mathrm{z}}(\mathrm{z})=0$ for $\mathrm{z}>\mathrm{R}$. For $\mathrm{z}<\mathrm{R}$,

$$
D_{z}(z)=\int_{-\sqrt{R^{2}-z^{2}}}^{\sqrt{R^{2}-z^{2}}} \int_{-\sqrt{R^{2}-z^{2}-y^{2}}}^{\sqrt{R^{2}-z^{2}-y^{2}}} Q d x d y=\pi Q\left(R^{2}-z^{2}\right) .
$$

Here, $\mathrm{Q}$ is the (constant) difference in the radiation source power per volume of the liquid and that of the bubble. That is; if the total radiation intensity is integrated over the surface of a volume $\mathrm{V}$ of the bulk fluid, and also over a similar volume of bubble, the difference between the two integrals is QV. The Fourier transform is straightforwardly found to be

$$
D_{z}\left(\frac{\omega}{v}\right)=\sqrt{8 \pi} Q\left(\frac{v}{\omega}\right)^{3}\left[\sin \left(\frac{\omega R}{v}\right)-\frac{\omega R}{v} \cos \left(\frac{\omega R}{v}\right)\right] .
$$

Evaluating this function at the frequency of interest, $\omega=\frac{2 \pi v}{k}$, we have

$$
D_{z}=\sqrt{8 \pi} Q\left(\frac{\mathrm{k}}{2 \pi}\right)^{3} \quad\left[\sin \left(\frac{2 \pi \mathrm{R}}{\mathrm{k}}\right)-\frac{2 \pi \mathrm{R}}{\mathrm{k}} \cos \left(\frac{2 \pi \mathrm{R}}{\mathrm{k}}\right)\right] .
$$

The $\mathrm{R}$ dependence of this function is indicated in Figure 5. This equation indicates that certain bubble sizes will produce zero output. That is; the velocity indicating peak will not be present if the bubble radius $R$ satisfies

$$
\frac{2 \pi R}{k}=\tan \left(\frac{2 \pi R}{k}\right)
$$

It may be possible to overcome this difficulty by a clever arrangement of different sizes and spacings of slots,. but it is expected that this will not be necessary since the bubbles will not all be the same size and there will be some bubbles that do not give zero output. 


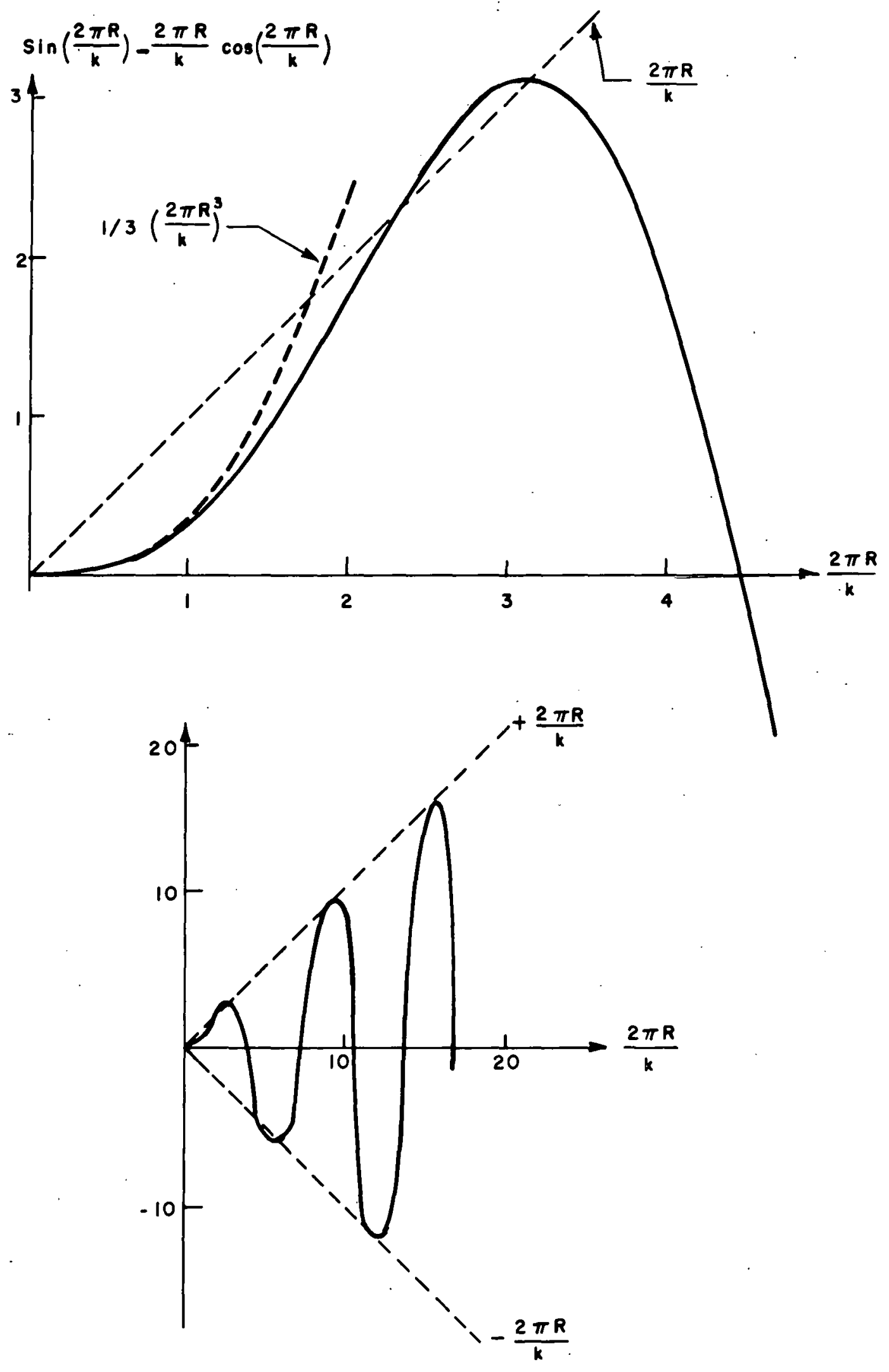

ANC-A-S106

Fig. 5 The $\mathrm{R}$ dependence of $D_{\mathrm{z}}$. 


\subsection{The Slot Geometry Function}

For the calculation of $\mathrm{I}_{\delta}$, assume that the grid material is a perfect absorber of the radiation. That is, there is no reflection or scattering of radiation from any surface, and no transmission through any thickness of the material. The slot and coordinate system are indicated in Figure 2. The point source of radiation is to the right of the slot, at some $x>0$. The slot width $w$ is assumed to be at least as large as the width of the sample region. A straightforward geometrical derivation yields an approximate expression for $\mathrm{I}_{\delta}$ :

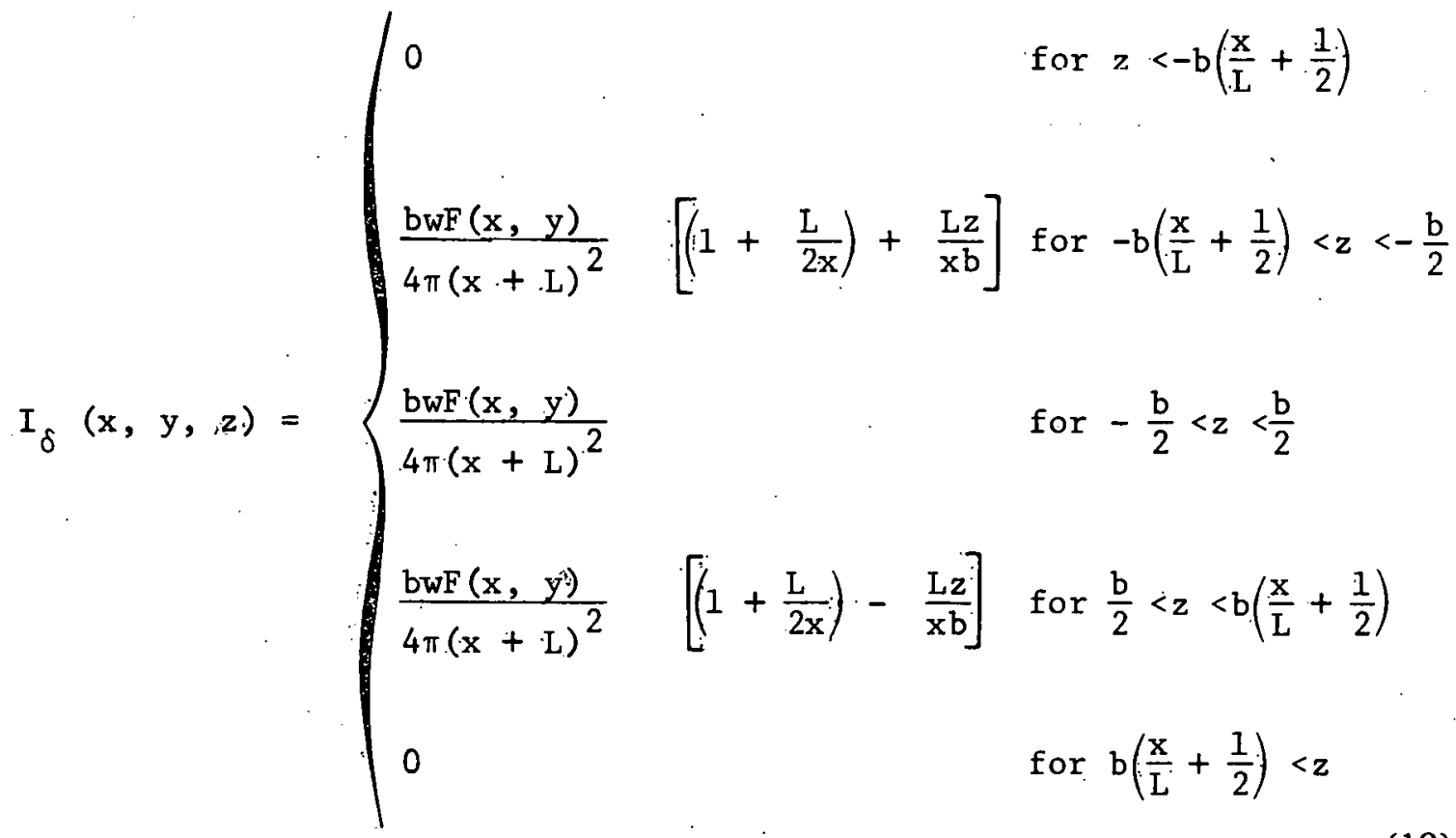

where

$$
F(x, y)=\frac{\frac{1}{2}-\frac{y}{w}}{\sqrt{1+\left(\frac{w / 2-y}{x+L}\right)^{2}}}+\frac{\frac{1}{2}+\frac{y}{w}}{\sqrt{1+\left(\frac{w}{2}+\frac{y}{x+L}\right)^{2}}} .
$$

This expression is derived by dropping terms smaller than $b^{2} / 2 L^{2}$ compared with 1 . This approximation introduces an error less than $1 \%$ for $b<0.1 \mathrm{~L}$, a typical case. The important aspect of $I_{\delta}$ is its $z$ dependence, which is indicated in Figure $6 . I_{\delta}\left(\frac{\omega}{v}\right)$ is obtainable by some tedious integration and algebra:

$$
\begin{aligned}
& I_{\delta}\left(\frac{\omega}{v}\right)=\frac{\omega b F\left(x_{o}, y_{o}\right)}{\left(x_{o}+L\right)^{2} \sqrt{2 \pi}^{3}}\left\{\frac{\sin \left(\frac{\omega b}{2 v}\right)}{\omega / v}-\frac{\sin \left(\frac{\omega b}{v}\left[\frac{x_{o}}{L}+\frac{1}{2}\right]\right)}{\omega / v}+\frac{2 \sin \left(\frac{\omega b x_{o}}{2 v L}\right)}{\omega / v}\right. \\
& \left.\left[\cos \left(\frac{\omega b}{2 v}\left[1+\frac{x_{o}}{L}\right]\right)+\frac{v L}{\omega x_{o} b} \sin \left(\frac{\omega b}{2 v}\left[1+\frac{x_{o}}{L}\right]\right)\right]\right\}
\end{aligned}
$$




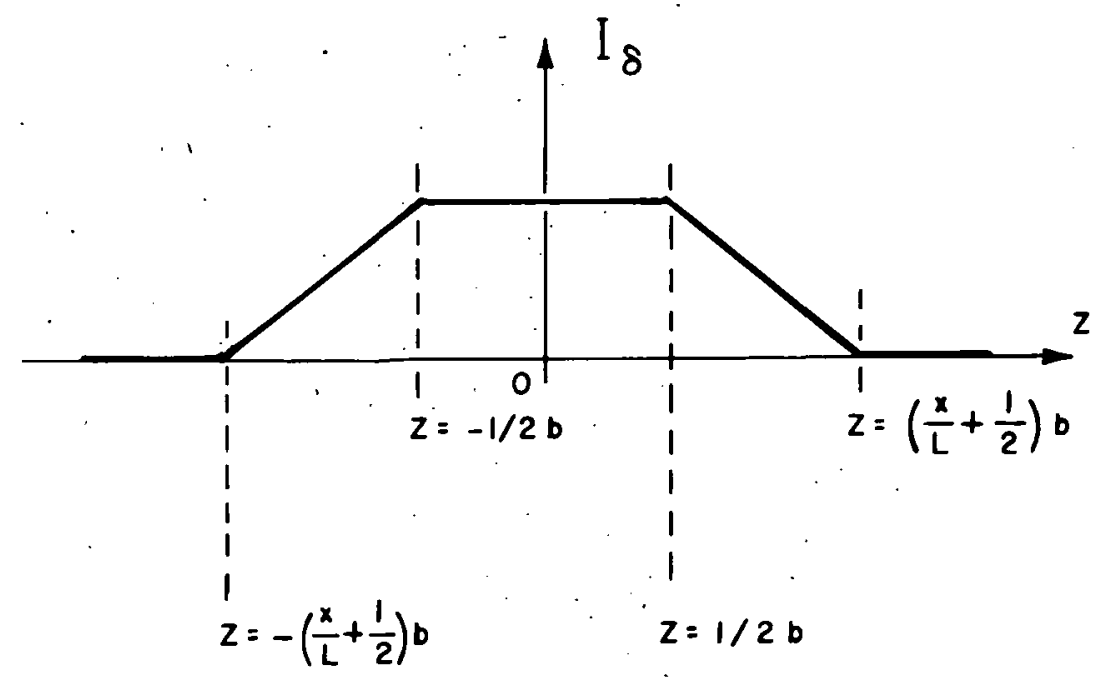

ANC-A-S107

Fig. 6 The $\mathrm{z}$ dependence of $\mathrm{I}_{\delta}$.

At $\omega=2 \pi v / k$, we have

$$
\begin{aligned}
I_{\delta}= & \frac{\operatorname{wbF}\left(\mathrm{x}_{\mathrm{o}}, \mathrm{y}_{\mathrm{o}}\right)}{\left(\mathrm{x}_{\mathrm{o}}+\mathrm{L}\right)^{2} \sqrt{2 \pi}^{3}}\left\{\frac{\sin \left(\frac{\pi \mathrm{b}}{\mathrm{k}}\right)}{2 \pi / \mathrm{k}}-\frac{\sin \left(\frac{2 \pi \mathrm{b}}{\mathrm{k}}\left[\frac{\mathrm{x}_{\mathrm{o}}}{\mathrm{L}}+\frac{1}{2}\right]\right)}{2 \pi / \mathrm{k}}+\right. \\
& \left.\frac{\sin \left(\frac{\pi \mathrm{bx}}{\mathrm{kL}}\right)}{\pi / \mathrm{k}}\left[\cos \left(\frac{\pi \mathrm{b}}{\mathrm{k}}\left[1+\frac{\mathrm{x}_{\mathrm{o}}}{\mathrm{L}}\right]\right)+\frac{\mathrm{kL}}{2 \pi \mathrm{bx}} \sin \left(\frac{\pi \mathrm{b}}{\mathrm{k}}\left[1+\frac{\mathrm{x}_{\mathrm{o}}}{\mathrm{L}}\right]\right)\right]\right\}
\end{aligned}
$$

Note that this indicates that the sensitivity is zero for bubbles at

$$
x_{0}=L\left(\frac{n k}{b}-1\right), \quad n=1,2,3, \ldots .
$$

and at

$$
\mathrm{x}_{\mathrm{o}}=\mathrm{L} \frac{\mathrm{nk}}{\mathrm{b}}, \mathrm{n}=1,2,3, \ldots
$$




\section{3:4. A Special Case: $k=2 b$.}

A great simplification can be brought about by considering the case in which the plates in the grid are as thick as the slots; that is, $\mathrm{k}=2 \mathrm{~b}$. Then.

$$
I_{\delta} D_{z}^{*}=\frac{w b^{4} Q F\left(x_{o}, y_{o}\right)}{\pi^{5} x_{o}^{2}} \frac{\sin \left(\frac{\pi x_{0}}{L}\right)}{\left(i+\frac{L}{x_{o}}\right)^{2}\left(\frac{\pi x_{0}}{L}\right)}\left[b \sin \left(\frac{\pi R}{b}\right)-\pi R \cos \left(\frac{\pi R}{b}\right)\right] .
$$

This function has zeros at

$$
\mathrm{x}_{\mathrm{o} .}=\mathrm{nL}, \mathrm{n}=1,2,3, \ldots
$$

(note Figures 7 and 8 ) and also at $R$ values that satisfy

$$
\frac{\pi \cdot R}{b}=\tan \left(\frac{\pi R}{b}\right)
$$

\subsection{Some Application Notes.}

Perhaps more insight into these equations can be gained by considering some aspects of practical applications. Let us consider the special case $\mathrm{k}=2 \mathrm{~b}$, and apply the system described by Equation (25) to a 14-inch outside diameter, 11.2-inch inside diameter pipe. The primary objective is to maximize the "sensitivity", or the amplitude of the velocity-indicating peak, which is proportional to the value of $I_{\delta} D_{Z}^{*}$ in Equation (25).

It is always best to place the grid as close as possible to the pipe; we will assume here that the grid is in contact with the pipe. Then $x_{o}$ is the distance from the outside surface of the pipe, at the grid, to the point inside the fluid where we wish to measure the velocity.

First let us consider $\mathrm{L}$, the length of the grid slots. If we want uniform sensitivity over the entire area of the pipe, then the slot length $\mathrm{L}$ should be large. However, increasing $\mathrm{L}$ tends to decrease the overall sensitivity. Therefore, some compromise is necessary between the uniformity of the sensitivity and the average magnitude of the sensitivity. This is indicated by the curves in Figure 9, which are just the curve from Figure 7 on the appropriate scales.

A better combination of high average sensitivity and uniformity across the pipe can be attained by the use of a pair of grid-detector assemblies, one on each side of the pipe. Compare, for example, the $L=21$ curve in Figure 10 with the $L=42$ curve in Figure 9. Note that these two configurations use the same volume and mass of grid material, although the dual-grid system uses twice as many detectors. 


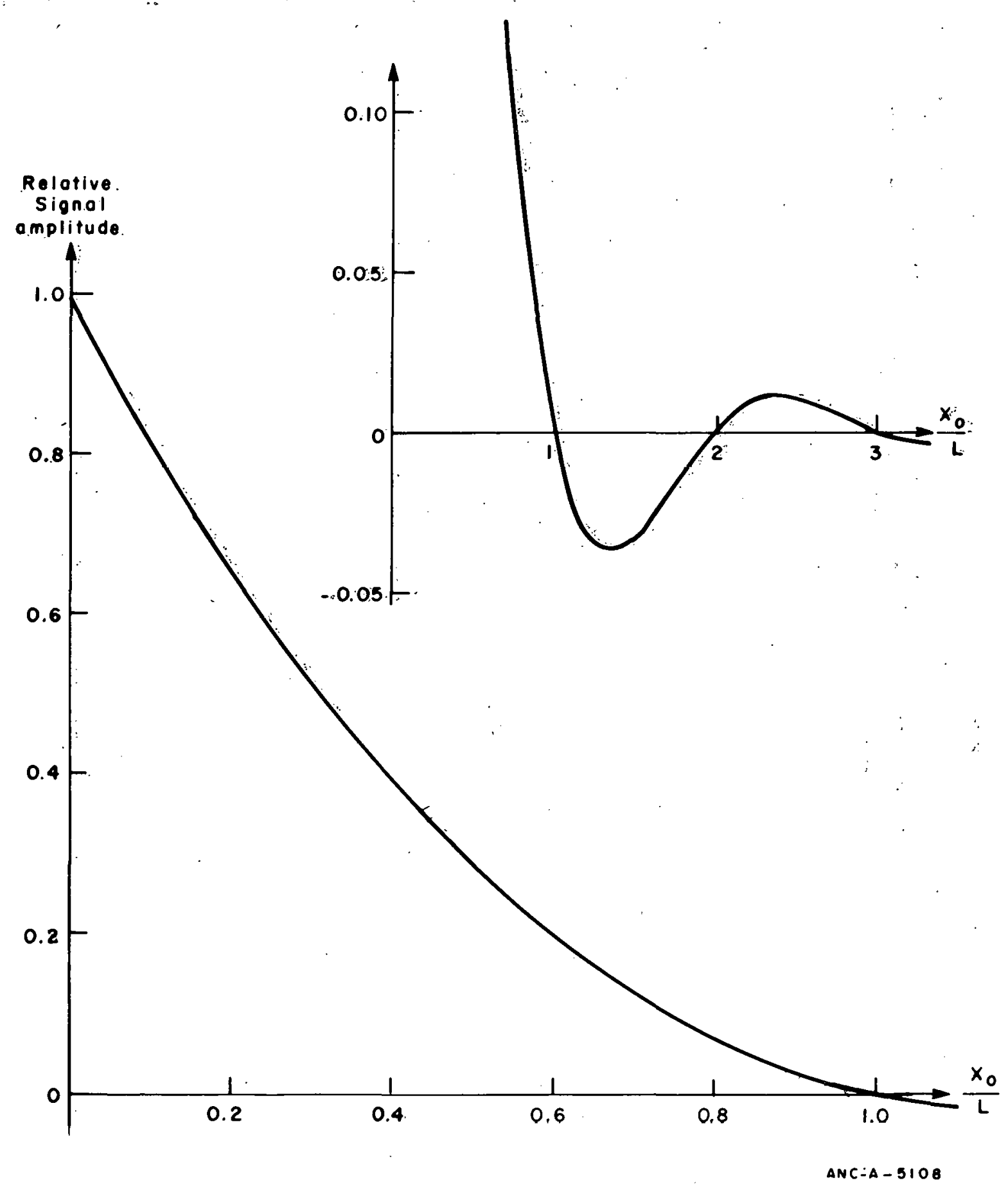

Fig. 7 Relative signal amplitude versus $x_{0}$ for fixed $L$, with $k=2 b$. 


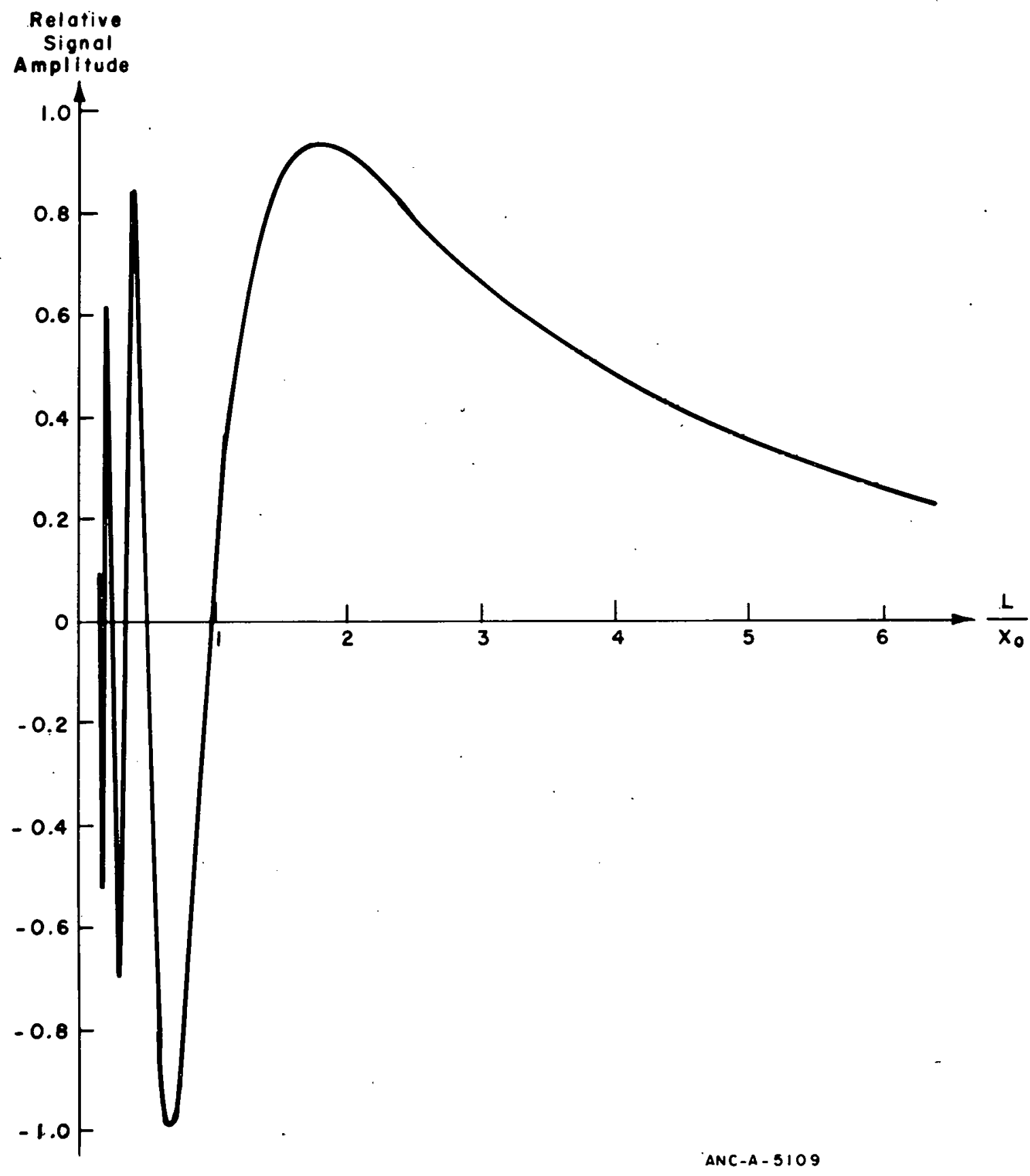

Fig. 8 Relative signal amplitude versus $L$ for fixed $x_{0}$, with $k=2 b$.

An alternative to looking at the whole pipe might be to look at a narrow region along a diameter of the pipe. If annular flow is assumed, a narrow beam with sensitivity proportional to the distance from the pipe center gives the same result as a whole-pipe system with uniform sensitivity. A single grid with slot length $L$ equal to the pipe radius gives a sensitivity curve which deviates by about $12 \%$ from a straight line, when the contributions from both halves of the pipe diameter are summed. The linearity cannot be 


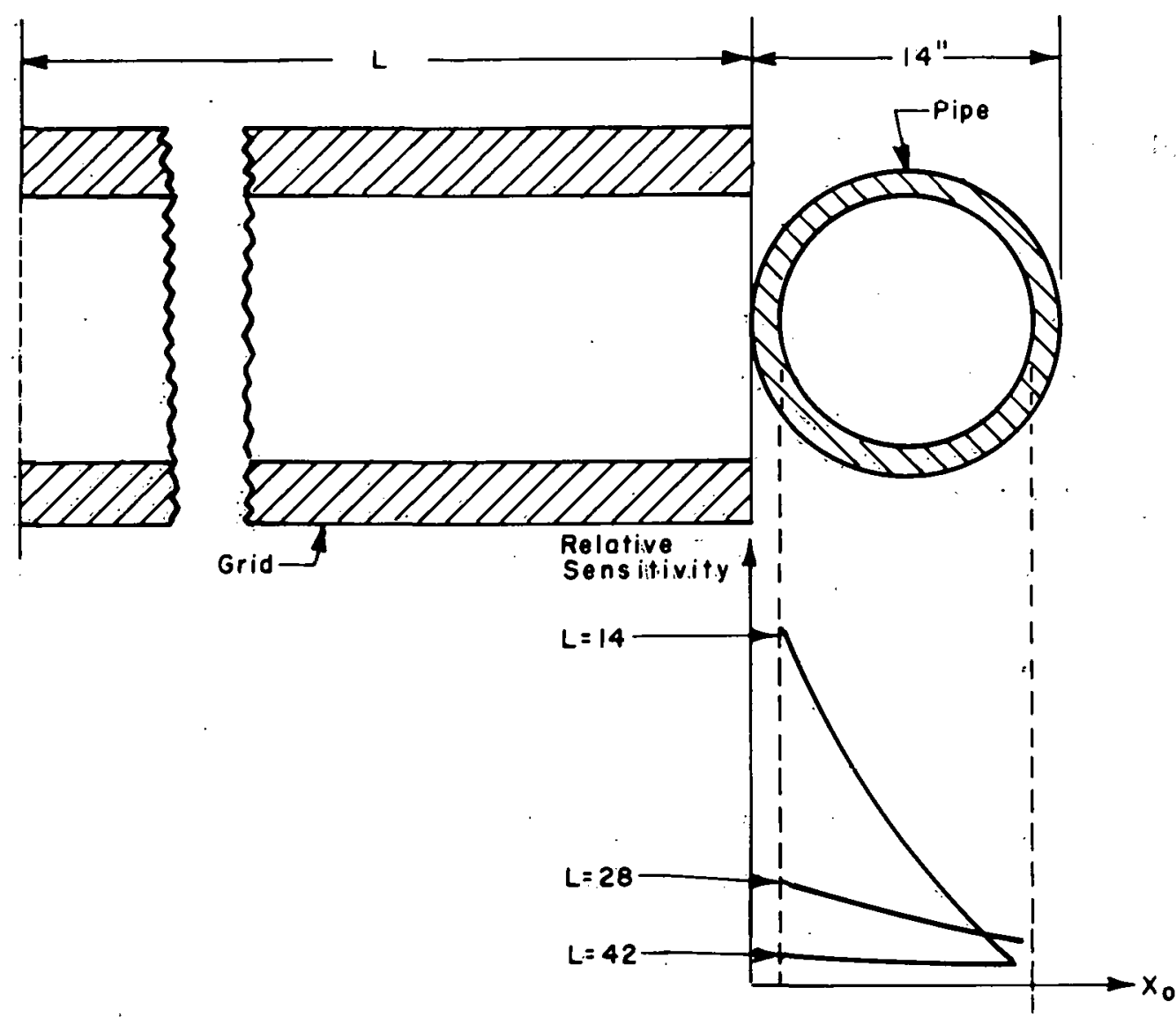

ANC-A - 5110

Fig. 9 Sensitivity versus $x_{0}$ for different $L$ values, for a single-grid, pipe-averaging system.

improved by using a dual-grid system. A dual-grid system with the two detectors connected in opposition can give a sensitivity curve which is within $3 \%$ of a straight line, but is positive on one side of the pipe and negative on the other side. This means that any bubble or cluster of bubbles centered in the pipe would give no signal.

In some applications, one might wish to maximize the sensitivity at a particular point in the pipe without regard to the sensitivity at other points. The graph in Figure 8 indicates that the maximum sensitivity at a point is obtained by making $\mathrm{L}=0.673 \mathrm{x}_{\mathrm{O}}$. Thus, if we wish to maximize the sensitivity at the center of a 14-inch diameter pipe, we should use $\mathrm{L}=$ $0.673 \times 7=4.71$ inches. The sensitivity curve for this configuration is sketched in Figure 11 . Note that, although the sensitivity is much higher at other parts of the pipe than it is at the center, there is no value of $\mathrm{L}$ that will give a larger sensitivity at the center. One can greatly decrease the sensitivity for small $x_{0}$, without much sacrifice in the sensitivity at the pipe center, by using $L=1.81 \times 7=12.66$ (note Figure 11 ). This corresponds to the broad, secondary extremum in the curve of Figure 8 . This configuration has the advantage that the signal from the pipe center is not so badly swamped by the relatively large signals from regions with small $\mathrm{x}_{\mathrm{o}}$. 


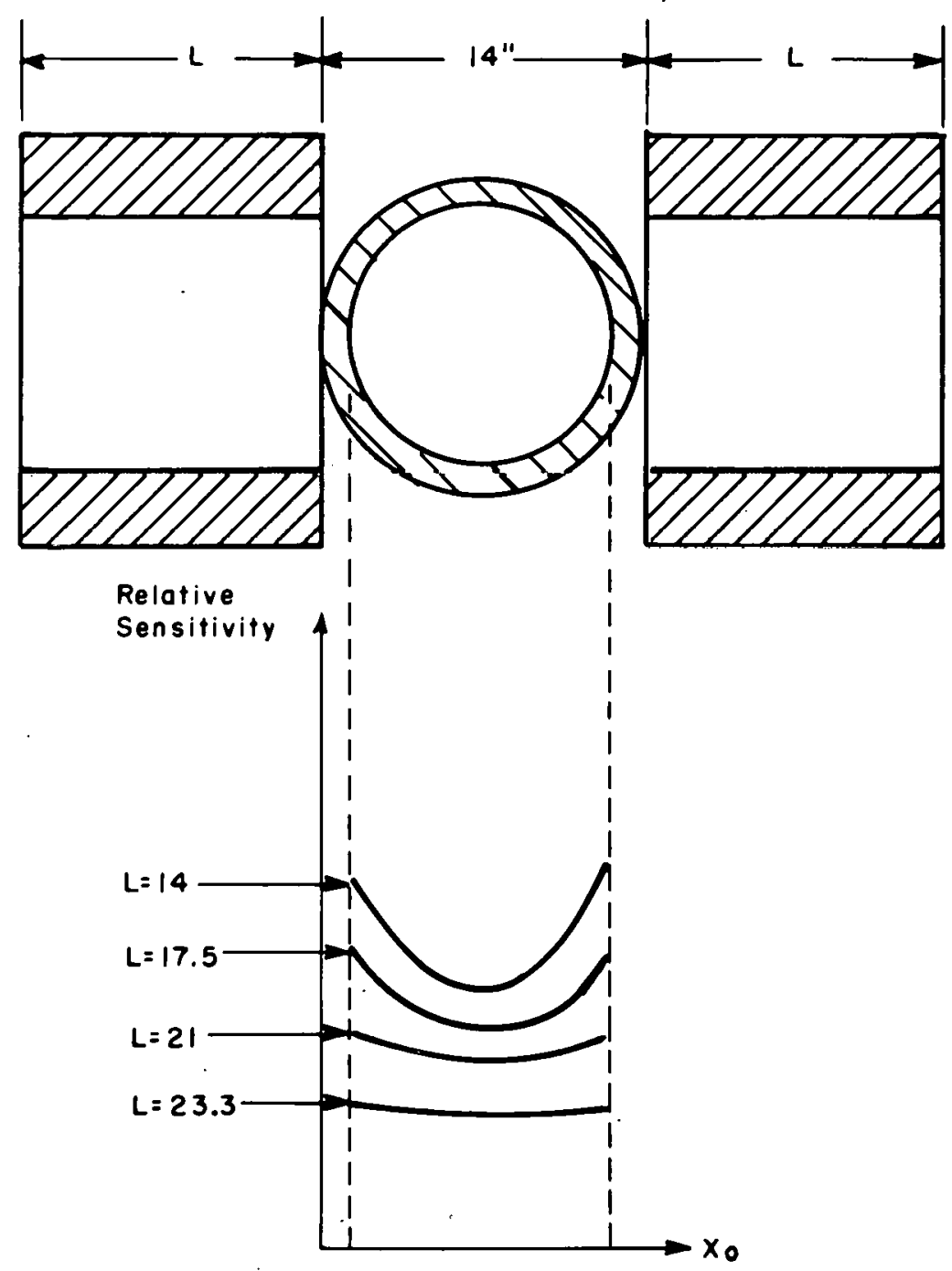

ANC-A-SIII

Fig. 10 Sensitivity versus $x_{0}$ for different $L$ values, for a dual-grid, pipe-averaging system.

These examples show that the best value for $\mathrm{L}$ is strongly dependent on the particular application, and that typical values for $L$ range from about one to several pipe diameters.

The slot thickness $\mathrm{b}$ and the number of slots $\mathrm{N}$ should be considered together. For small bubbles, Equations (14) and (25) indicate that the sensitivity depends on the product $\mathrm{Nb}^{2}$ for small bubbles or $\mathrm{Nb}^{4}$ for large bubbles. Therefore, both $\mathrm{N}$ and b should be as large as possible. If there are space limitations, the product $\mathrm{Nb}$ will be constrained to some maximum value. In this case, it is better to make $\mathrm{N}$ small and $\mathrm{b}$ large. Of course, $\mathrm{N}$ must not be too small, or the peaks in the spectrum are not sharp (note Figure 4), and it is hard to locate the center frequency with any precision. It will be noted in Section 5 that increasing $\mathrm{N}$ degrades the signal-to-noise ratio. 


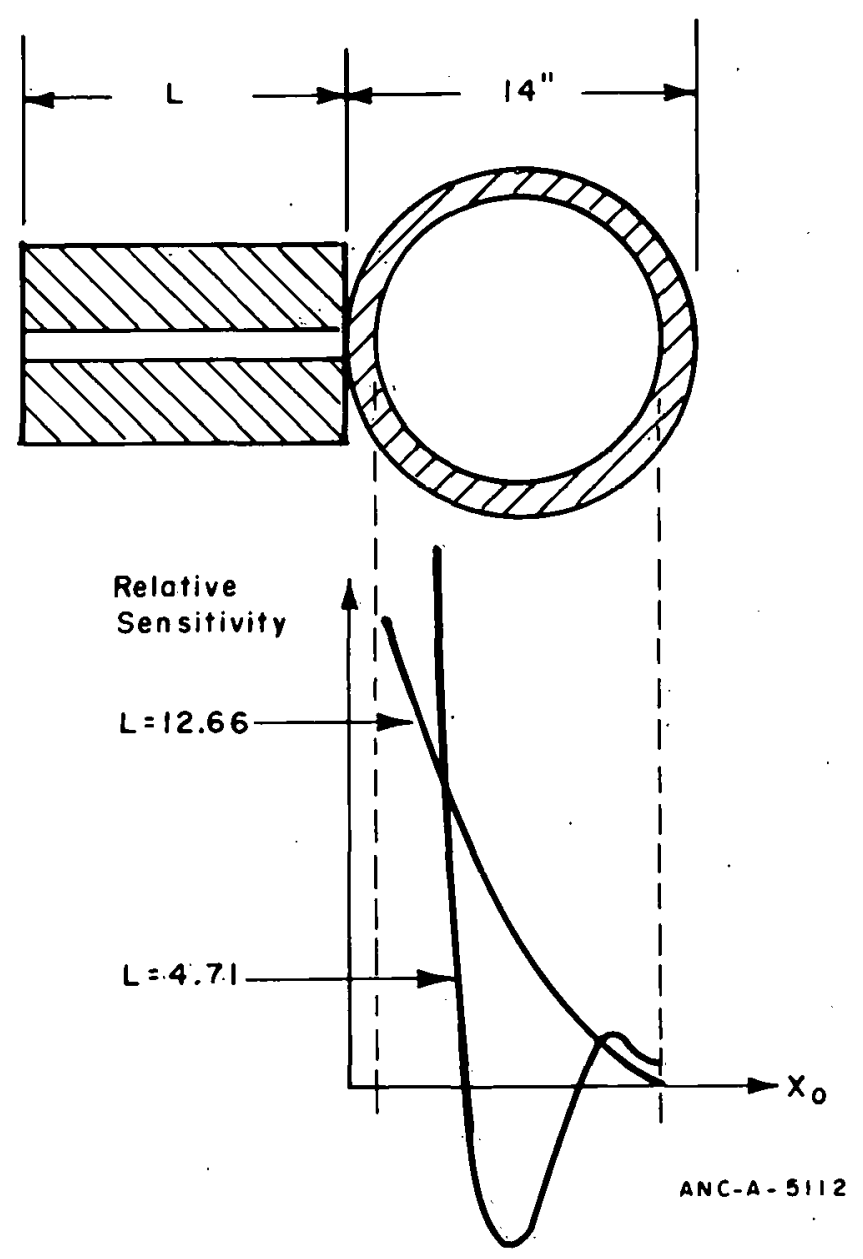

Fig. 11 Sensitivity versus $x_{0}$, with sensitivity maximized at the pipe center, for a single-grid system.

There is another limit on $\mathrm{Nb}$ : if the product $2 \mathrm{Nb}$ is greater than the average distance that a density fluctuation travels before diffusing away, increasing $\mathrm{Nb}$ serves only to increase the noise in the system. However, this is not expected to occur in most applications.

As was implied in an assumption in Section 3.3, the slot width w should be about as large as the width of the measurement region: 


\section{AN ABSORBING FLUID WITH AN EXTERNAL RADIATION SOURCE}

The requirements for this treatment to apply to an absorbing, nonradioactive fluid with an external radiation source are two:

(1) The radiation source must supply a beam broad enough to illuminate the entire grid, and isotropic enough to fill the entire angular acceptance region of the grid.

(2) The change in the beam intensity due to radiation absorption by an inhomogeneity must be not more than a few percent. That is, we must have

$$
e^{-\left(\delta_{1}-\delta_{2}\right) R}=1-\left(\delta_{1}-\delta_{2}\right) R
$$

to a good approximation, where $\delta_{1}$ and $\delta_{2}$ are the radiation attenuation coefficients of the two fluid phases and $R$ is the size of the inhomogeneity.

Violation of this second requirement would not produce any large changes in the theory presented; it would cause some minor changes in the shapes of the spectra discussed. Violation of the first requirement could cause major changes in the fundamental properties of the spectra. 


\section{NOISE}

The primary limitation of this general technique is that the velocity-indicating peak - 3 . can be obscured by noise in the spectrum. This noise comes primarily from two sources: statistical fluctuations in the radiation source intensity, and uncorrelated random fluctuations in the fluid density. The noise due to the electronics is insignificant in this type of device. The magnitude of the noise due to the uncorrelated density fluctuations is difficult to estimate, and of course is very dependent on the two-phase fluid flow regime. It will not be dealt with here, other than to comment that this noise is expected to be small compared with the noise due to source intensity fluctuations. The noise in the spectrum due to source intensity fluctuations depends strongly on the techniques used in taking the Fourier transform. However, the noise in $A(t)$ is not hard to estimate, and we can use a crude rule of thumb that if the amplitude of the signal in $\mathrm{A}(\mathrm{t})$ (as in Figure 3 ) is as large as the noise level, then we can probably extract the velocity information.

The noise in $\mathrm{A}(\mathrm{t})$ due to statistical fluctuations in the source intensity is $[1]$

$$
\sigma=\alpha \sqrt{\frac{n}{2 \tau}}
$$

where $\sigma$ is the rms noise level in $A(t), n$ is the average number per second of radiation quanta or particles detected by the system, and $\tau$ is the time constant of the electronics associated with the radiation detectors.

For a system in which the fluid itself is the radiation source, we can make a crude estimate of $n$ by

$$
\begin{gathered}
\mathrm{n}=\text { Qo } \mathrm{x} \text { [effective source volume per grid slot] } \mathrm{N} \mathrm{x} \\
\mathrm{x}[\text { solid angle subtended by a grid slot] } \\
\simeq \text { Qo } \mathrm{wbx} \frac{\mathrm{wb}}{4 \pi \mathrm{L}^{2}} \mathrm{~N}=\text { QoNX } \frac{\mathrm{w}^{2} \mathrm{~b}^{2}}{4 \pi \mathrm{L}^{2}}
\end{gathered}
$$

where $\mathrm{X}$ is the dimension of the radioactive fluid in the $\mathrm{x}$ direction and $\mathrm{Q}_{\mathrm{O}}$ is the average radiation source intensity of the fluid. Similarly, the change in $A(t)$ caused by a small bubble's passing is roughly

$$
\delta \mathrm{A}=\alpha \delta \mathrm{n} \simeq \alpha \mathrm{Q} \frac{4}{3} \pi \mathrm{R}^{3} \frac{\mathrm{wb}}{4 \pi \mathrm{L}^{2}}=\alpha Q \mathrm{R}^{3} \frac{\mathrm{wb}}{3 \mathrm{~L}^{2}} .
$$


Then, the signal-to-noise ratio is roughly

$$
\frac{\delta \mathrm{A}}{\sigma} \simeq \frac{\mathrm{R}^{3}}{3 \mathrm{~L}} \sqrt{\frac{8 \tau \mathrm{Q} \sigma \pi}{\mathrm{NX}}}
$$

using $\mathrm{Q}_{\mathrm{O}} \cong \mathrm{Q}$ for a gas bubble in a radioactive liquid.

For a system with an external radiation source, we can write a rough approximation for the fractional change in $A(t)$ caused by the passing of the bubble of radius $R$ :

$$
\frac{\delta A}{A} \simeq \frac{4 \pi \mu R^{3}}{3 N w b}
$$

where $\mu$ is the linear attenuation coefficient for the radiation in the liquid. An expression for $n$ can be written after some details of the source geometry are known; and then an expression for $\delta \mathrm{A} / \sigma$, similar to Equation (32), can be written for this case of the external radiation source.

By these general procedures, the expressions for $\delta \mathrm{A} / \sigma$ can be used to estimate the signal-to-noise ratio for any given bubble size, and this information gives some idea about how well the particular system under consideration might work. 


\section{VARIATIONS}

One variation of the basic system has already been discussed: the use of radiation from the fluid itself rather than radiation from an external source. Another possibility is the use of radiation 'from the reactor, in reactor applications in which conditions are suitáble. A third possibility is the use of the radiation scattering by the inhomogeneities, rather ${ }^{\prime \prime}$ than using transmitted radiation.

If the grid slots are far apart, it might be necessary to use a separate radiation source and a separate detector for each slot, with the detector outputs added before entering the spectrum analyzer. Note Figure 12b. The use of separate sources will allow shorter grids (small L). This arrangement is sensitive to a region extending across the full width of the pipe. If the several source-detector pairs are rotated by different amounts about an axis parallel to the pipe axis, the region of sensitivity will be reduced to a small region near the axis of rotation, as in Figure 12c.

In some cases, it is necessary for the grid slots to be longer than the pipe diameter, making a rather cumbersome apparatus. A different type of grid, sketched in Figure 13 (not to scale), would allow a more compact system. Here a moving bubble causes the shadow of the front grid to move across the rear grid, giving an alternating intensity into the detector. This system has not yet been analyzed in detail, but it is expected that the region of sensitivity is quite localized, as indicated in the figure, especially with a wrap-around configuration.

It might be possible to improve the signal-to-noise ratio by using a time-delay cross-correlation of the several beam intensities, rather than Fourier analyzing their sum. 

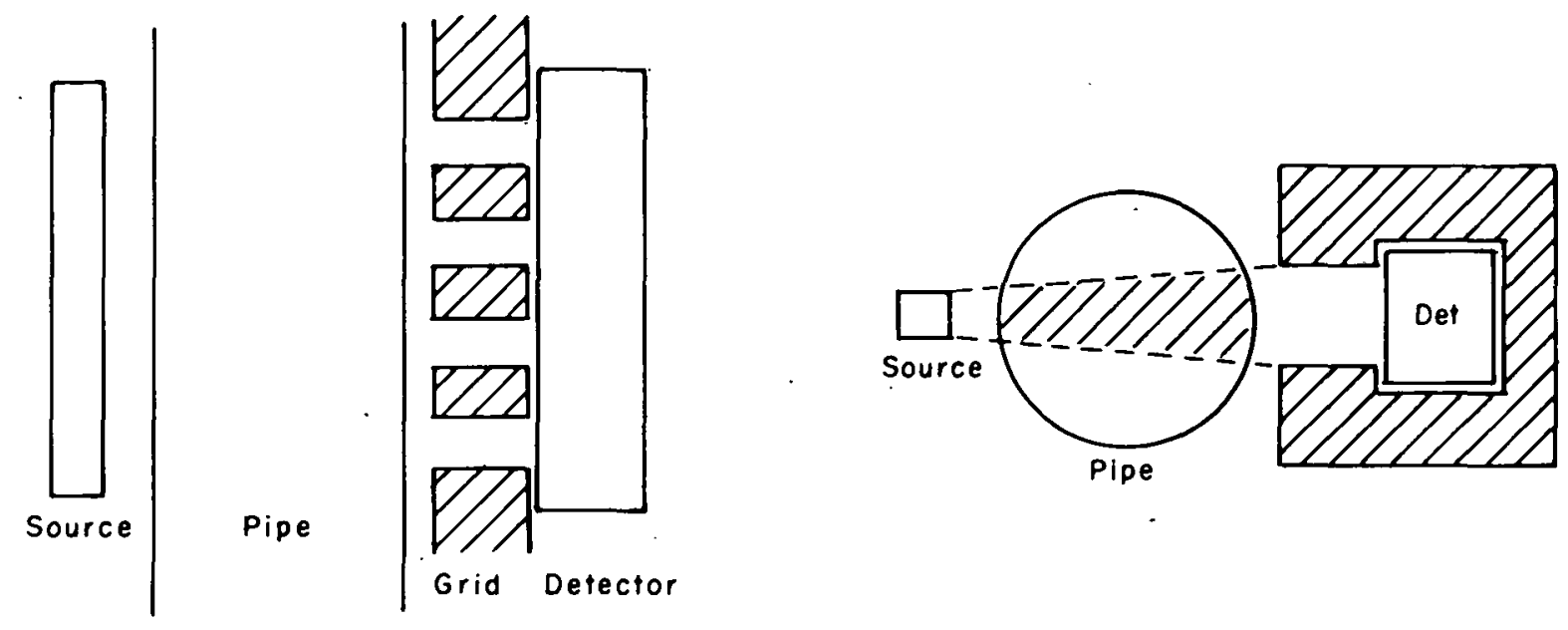

Fig. 12a Rasir, design.
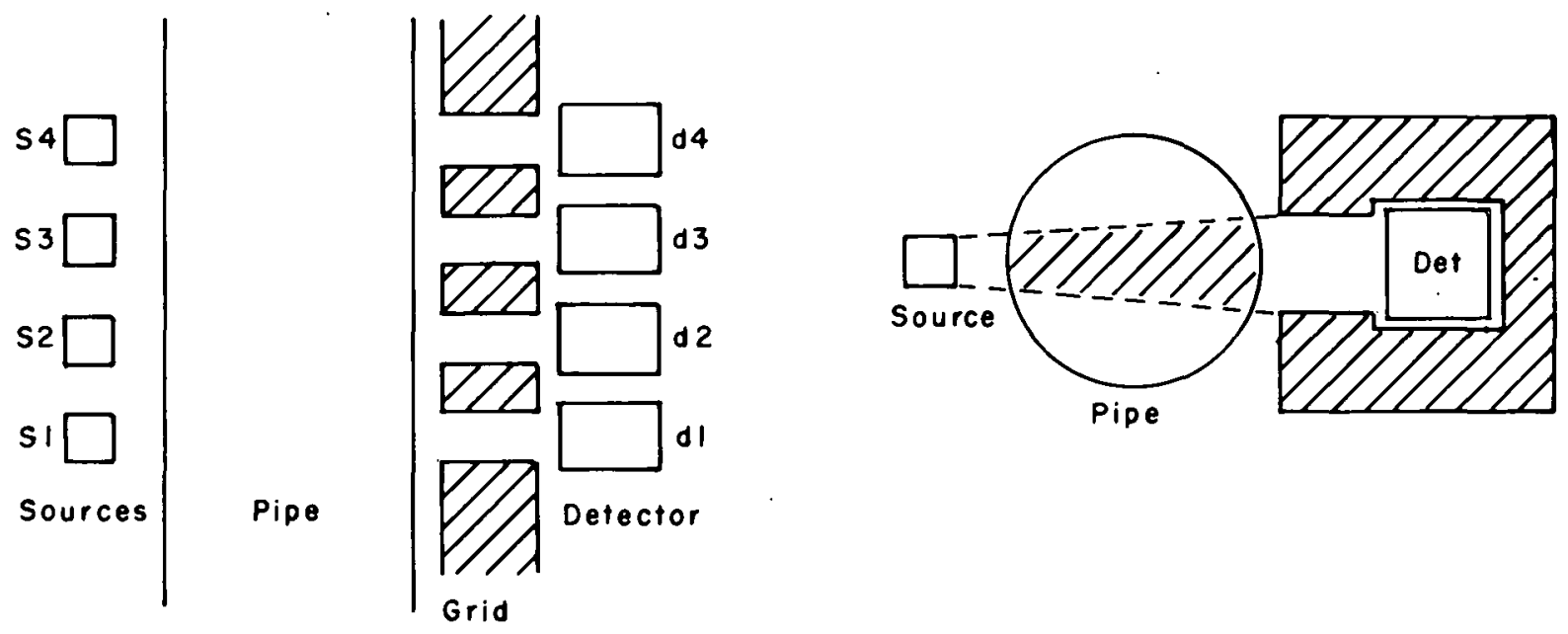

Fig. 12b Separate source and detector for each slot.
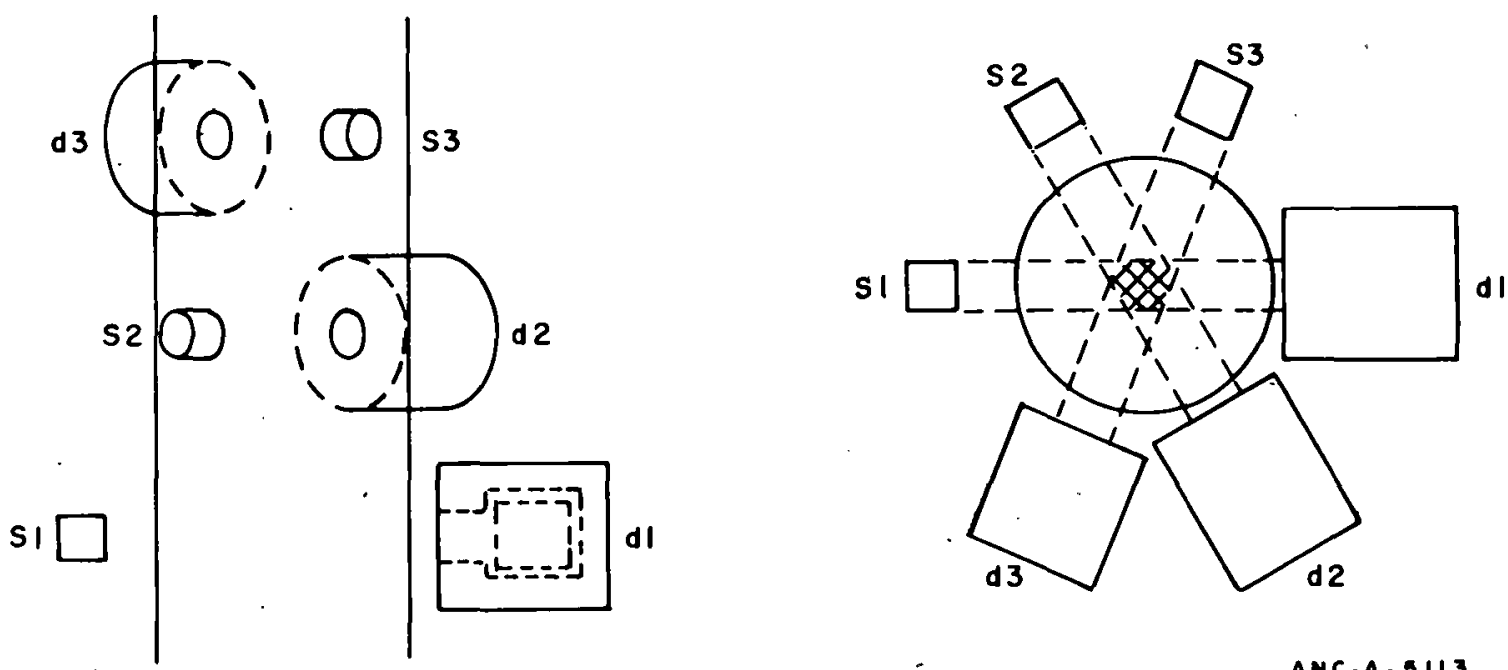

Fig. 12c Source-detector pairs rotated to reduce the area of sensitivity. 

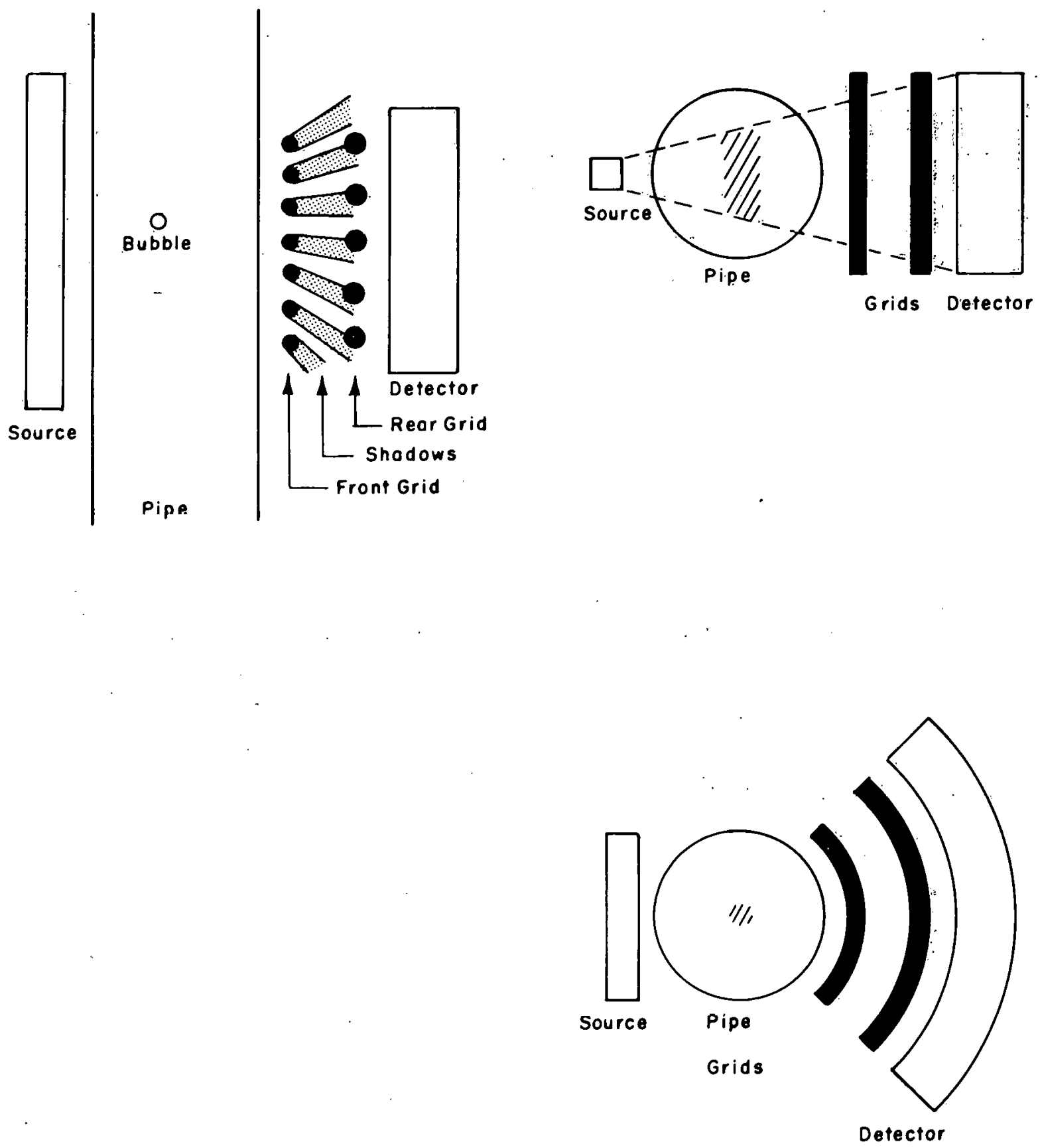

$A N C-A=51.14$

Fig. 13 A different grid configuration, and a wrap-around design. 


\section{EXPERIMENTAL DEMONSTRATION}

This experiment was done rather quickly, with available materials. A 15-curie gamma source was used to supply the radiation. The fluid was water with air bubbles, in a $9.5-\mathrm{mm}$ inside diameter Tygon tube. The bubbles almost filled the tube so that the flow pattern was nearly slug flow. A standard scintillation crystal and photomultiplier combination was used as a detector, and the spectrum analyzer was a General Radio model 1900-A. The aperture in the shielding limited the radiation beam to an area $16 \mathrm{~mm}$ in diameter, and the grid had to be contained in this area. Because of this size limitation, it was not possible to have a large number of large slots, as would have been desirable. However, some success was obtained with only two slots, and very limited success with three small slots. The experimental arrangement is shown in Figures 14 and 15.

Some spectra obtained with this arrangement are shown in Figure 16. These are strip chart recordings of $\log$ power versus frequency, with the vertical scale representing a $40 \mathrm{~dB}$ range. The top two spectra were obtained with a two-slot grid; one spectrum is offset by 20 $\mathrm{dB}$ from the other. The zero frequency peak and the $60 \mathrm{~Hz}$ noise peaks are marked. The shoulder at about $10 \mathrm{~Hz}$ is due to the bubble frequency; that is, about 10 bubbles per second pass through the system. This peak will be present with any number of slots from one on up, as long as one bubble at a time passes through the gamma beam. The peak at about $39 \mathrm{~Hz}$ in the top pair of spectra is the desired velocity indication. Since the slot spacing was about $1 \mathrm{~cm}$, the bubble velocity was about $39 \mathrm{~cm} / \mathrm{sec}$. This is in good agreement with velocity estimates made with a simple time and distance measurement method. The bottom spectrum shows a weak indication of a peak near about $46 \mathrm{~Hz}$, but obviously the peak is too weak to locate accurately. Sharper peaks would be expected with more slots, but in this case the three slots are so narrow that the signal is weak. It is expected that a properly designed system would give much better results than this makeshift arrangement. 


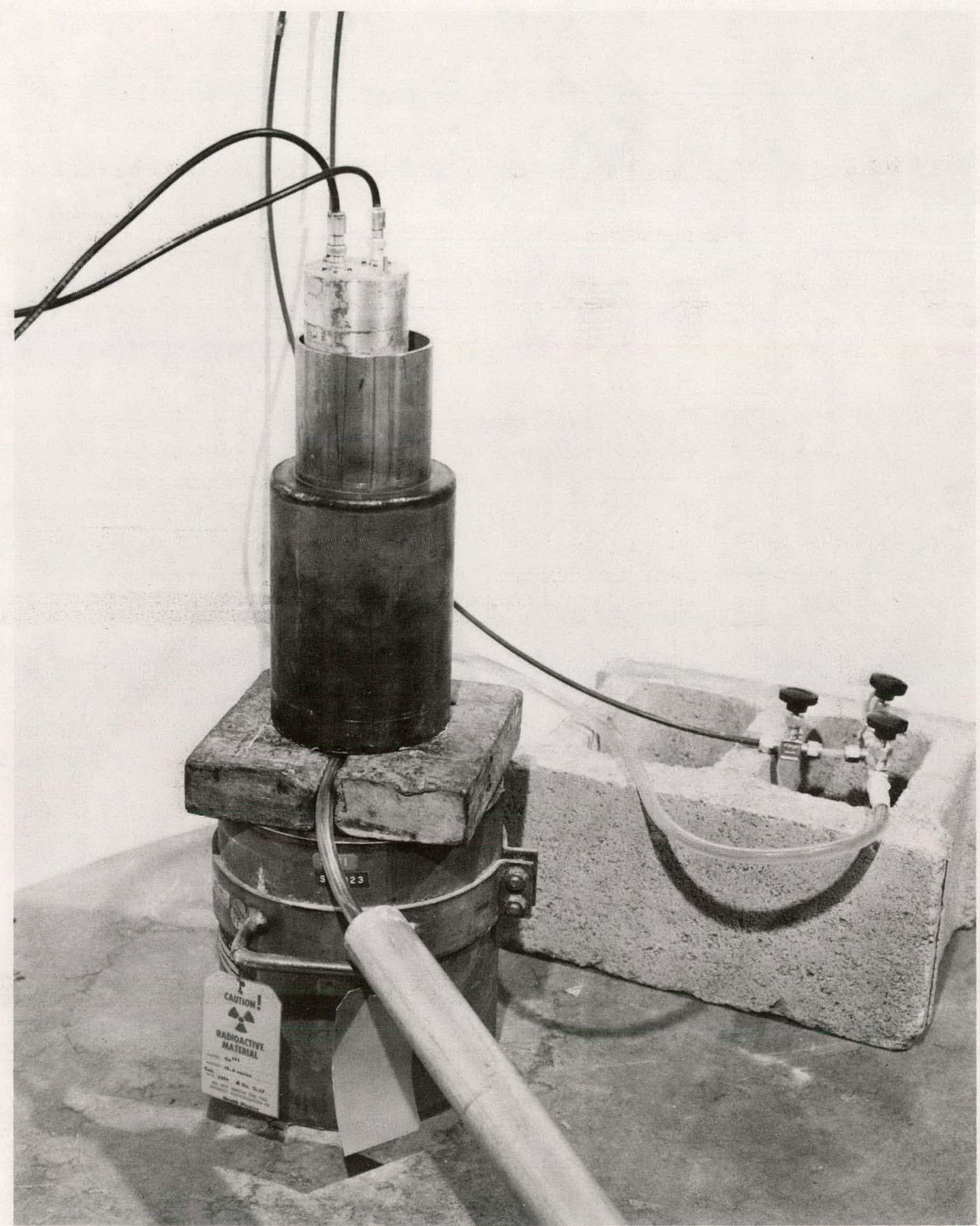

Fig. 14 Photograph of the experimental apparatus. 


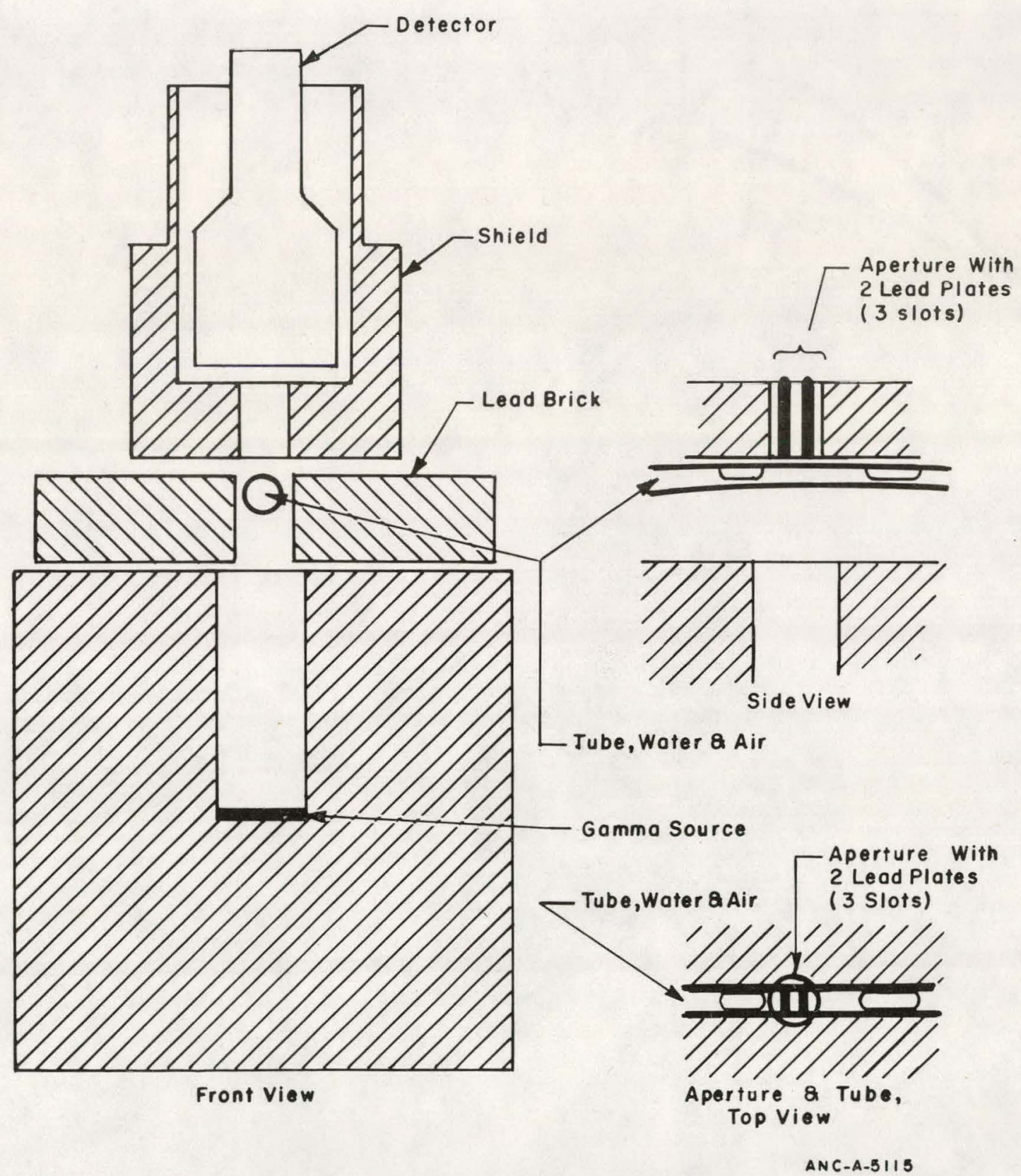

Fig. 15 Sketch of the experimental apparatus. 

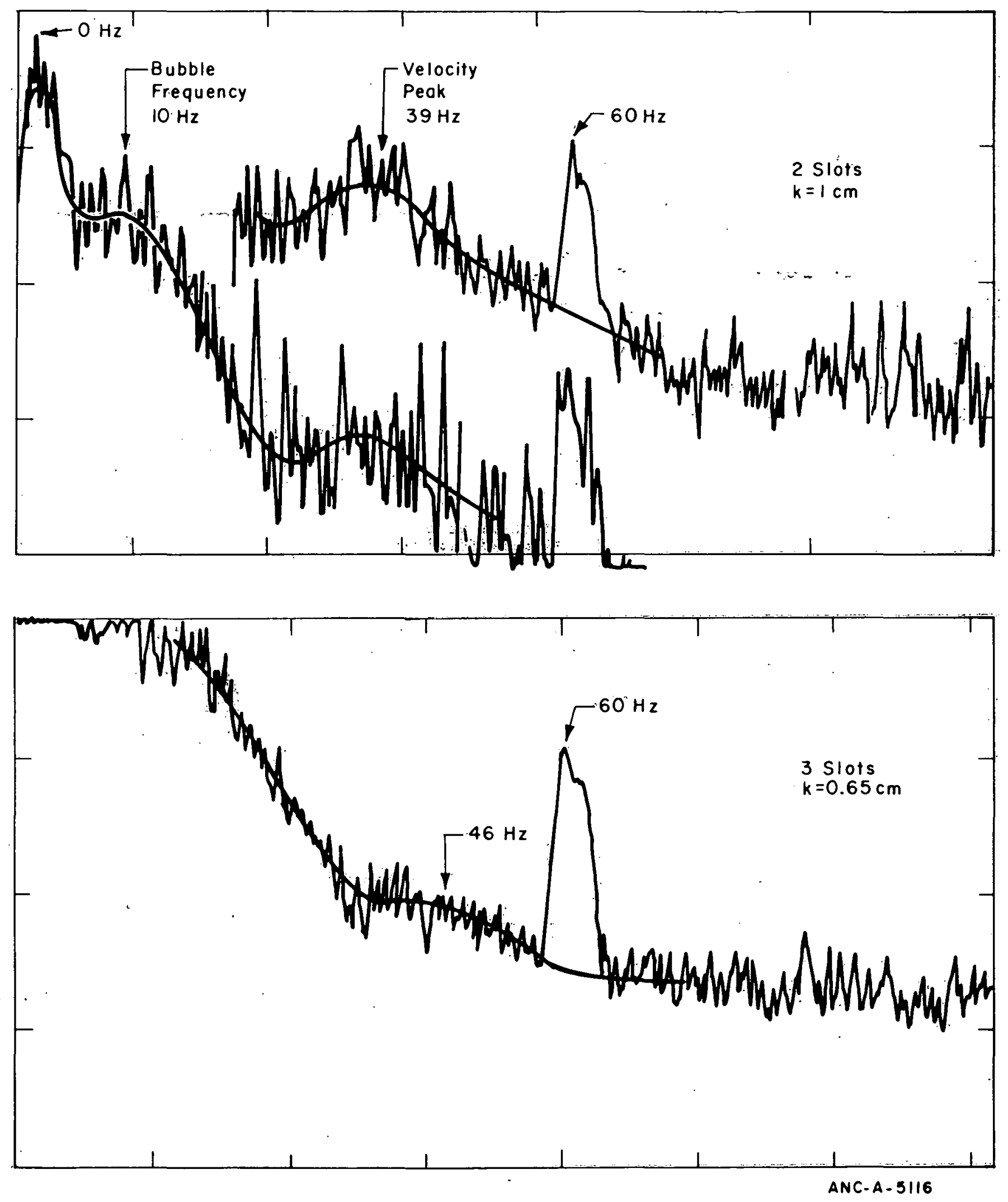

Fig. 16 Sample spectra from experiment. 


\section{CONCLUSIONS}

This method of measuring the velocity of two-phase fluid flow actually measures the velocities of inhomogeneities, such as steam bubbles in water or water drops in steam. If different parts of the region being measured have fluids flowing at different velocities, there is a separate indication of each velocity component in the output. This system has some potential for mapping the velocity distribution across the pipe, and it does not interfere with the fluid flow.

The main difficulties with this method are that it may require rather large, cumbersome apparatus in some applications, and it may require quite intense radiation sources. This method is not very sensitive to very small bubbles or to certain sizes of larger bubbles. This last is not a severe limitation, since there will usually be a considerable distribution of bubble sizes if there are any bubbles at all.

The basic principles have been confirmed with a simple experiment, and the difficulties do not seem insurmountable. This technique can probably measure velocities in extreme two-phase flow conditions where turbines are not very accurate. Further development seems appropriate. 
9. REFERENCE

1. T. C. Piper, Dynamic.Gamma Attenuation Density Measurements, ANCR-1160 (May 1974). 


\section{DISTRIBUTION RECORD FOR ANCR-1216}

\section{External}

287 - NRC-2 - Water Reactor Safety Research Systems Engineering Additional External

1 - R. Feit

1 - R. VanHouten

1 - W. V. Johnson

1 - Y. Y. Hsu

\section{Internal}

1 - Chicago Patent Group - ERDA 9800 South Cass Avenue

Argonne, Illinois 60439

3 - A. T. Morphew, Classification and Technical Information Officer ERDA-ID

Idaho Falls, Idaho 83401

31 - INEL Technical Library

20 - Special Internal Distribution

20 - Author 